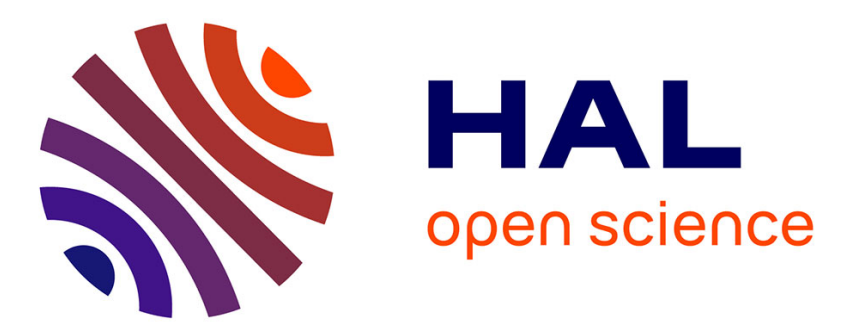

\title{
Epimerization and chain scission of polylactides in the presence of an organic base, TBD
}

Julie Meimoun, Audrey Favrelle-Huret, Marc Bria, Nicolas Merle, Grégory Stoclet, Julien de Winter, Rosica Mincheva, Jean-Marie Raquez, Philippe Zinck

\section{To cite this version:}

Julie Meimoun, Audrey Favrelle-Huret, Marc Bria, Nicolas Merle, Grégory Stoclet, et al.. Epimerization and chain scission of polylactides in the presence of an organic base, TBD. Polymer Degradation and Stability, 2020, 181, pp.109188. 10.1016/j.polymdegradstab.2020.109188 . hal-03247354

\section{HAL Id: hal-03247354 \\ https://hal.univ-lille.fr/hal-03247354}

Submitted on 3 Jun 2021

HAL is a multi-disciplinary open access archive for the deposit and dissemination of scientific research documents, whether they are published or not. The documents may come from teaching and research institutions in France or abroad, or from public or private research centers.
L'archive ouverte pluridisciplinaire HAL, est destinée au dépôt et à la diffusion de documents scientifiques de niveau recherche, publiés ou non, émanant des établissements d'enseignement et de recherche français ou étrangers, des laboratoires publics ou privés. 
Epimerization and chain scission of polylactides in the presence of an organic base, TBD

Julie Meimoun, ${ }^{\mathrm{a}}$ Audrey Favrelle-Huret, ${ }^{\mathrm{a}}$ Marc Bria, ${ }^{\mathrm{b}}$ Nicolas Merle, ${ }^{\mathrm{a}}$ Grégory Stoclet, ${ }^{\mathrm{c}}$ Julien De Winter, ${ }^{\mathrm{d}}$ Rosica Mincheva, ${ }^{\mathrm{e}}$ Jean-Marie Raquez, ${ }^{\mathrm{e}}$ Philippe Zinck ${ }^{\mathrm{a}^{*}}$

${ }^{a}$ Univ. Lille, CNRS, Centrale Lille, Univ. Artois, UMR 8181 - UCCS - Unité de Catalyse et Chimie du Solide, F-59650 Villeneuve d'Ascq, France. philippe.zinck@univ-lille.fr

${ }^{\mathrm{b}}$ Univ. Lille, CNRS, Centrale Lille, Univ. Artois, FR 2638 - IMEC - Plateforme RMN Institut Michel-Eugène Chevreul, F-59650 Villeneuve d'Ascq, France.

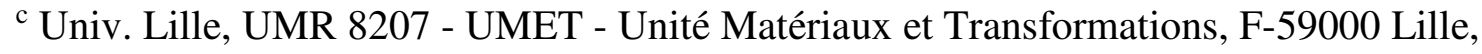

${ }^{\mathrm{d}}$ Interdisciplinary Center for Mass Spectrometry, Organic Synthesis and Mass Spectrometry Laboratory, University of Mons - UMONS, 23 Place du Parc, 7000 Mons, Belgium

${ }^{\text {e }}$ Service des Matériaux Polymères et Composites, Centre d'Innovation et de Recherche des Matériaux et Polymères (CIRMAP), Service des Matériaux Polymères et Composites (SMPC), Université de Mons, Place du Parc 20, B7000 Mons, Belgique 


\begin{abstract}
The epimerization of polylactide is reported in the presence of 1,5,7triazabicyclo[4.4.0]dec-5-ene (TBD) at $105^{\circ} \mathrm{C}$ in toluene. The extent of the reaction depends on the amount of TBD introduced and the reaction time. Up to $c a .46 \% \mathrm{D}$ units can be formed starting from poly(L-lactide) in the presence of $5 \mathrm{~mol} \% \mathrm{TBD}$. The epimerization rate is slightly higher for D-stereoisomers vs. L-stereoisomers. From the decrease of the number-average molecular weight observed, a concomitant chain scission reaction is observed. A possible mechanism based on a nucleophilic attack of TBD is proposed based on NMR analyses, notably DOSY, MALDI ToF mass spectrometry and IR spectroscopy. The implications of the work in the field of polymer synthesis and chemical recycling of polylactide are discussed.
\end{abstract}

Keywords : polylactide, epimerization, racemization, organocatalysis, recycling 


\section{Introduction}

Polylactide is a biobased polymer available at the industrial scale. Although also obtainable by the polycondensation of lactic acid, polylactide is usually produced by the ringopening polymerization of diastereomeric lactides (Scheme 1). Over the last two decades, as an alternative to metal based catalysts, a huge interest has risen in the quest for organocatalysts for polymerization reactions including the latter.[1] [2] [3] [4] [5] Among them, nitrogeneous bases were found to be highly efficient catalysts,[6] [7] [8] [9] [10] [11] [12] [13] [14] due notably to the versatility of their activation mode. The nitrogen atom can indeed lead to the activation of a protic (co-)initiator and/or a direct nucleophilic attack of the catalyst on the lactide monomer, depending on the catalyst's structure.[15] [16] [17] [18] H-bonding mechanisms are also operating in some cases.[19] [20] [21]

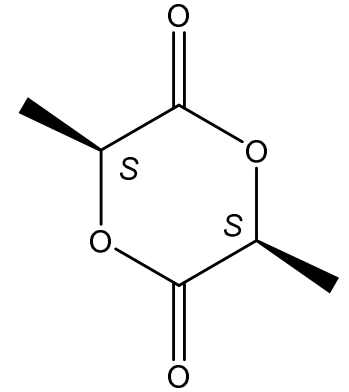

L-lactide

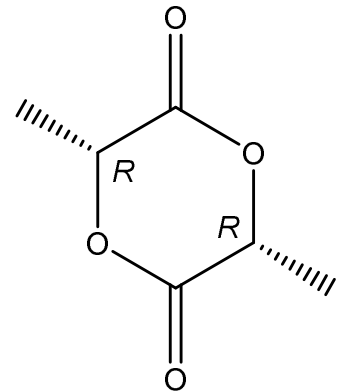

D-lactide<smiles>C[C@@H]1OC(=O)[C@H](C)OC1=O</smiles>

meso-lactide

Scheme 1 Diastereomeric lactides

$\mathrm{N}$-heterocyclic bases were also reported as catalysts for the depolymerization of polylactide in combination with protic compounds, leading to alkyl lactates and oligomers.[22] [23] Another reaction that is catalyzed by these bases is epimerization. This stereochemical inversion has been studied on L-lactide without catalyst in bulk conditions.[24] The formation of meso-lactide is observed at temperatures higher than $200^{\circ} \mathrm{C}$, up to $c a .40 \%$, together with the 
formation of oligomers. Meso-lactide can itself be epimerized into L- and D-lactides in the presence of an equimolar amount of nitrogeneous bases such as 1,4-diazabicyclo [2.2.2]octane (DABCO), 1,8-diazabicyclo[5.4.0]undec-7-ene (DBU) and imidazole in toluene.[25] The reaction proceeds at room temperature for the amidine, while higher temperatures are required for $\mathrm{DABCO}$ and imidazole. When combining $\mathrm{DABCO}$ with a Lewis acid such as $\mathrm{B}\left(\mathrm{C}_{6} \mathrm{~F}_{5}\right)_{3}$, the epimerization of meso-lactide into rac-lactide (an equimolar mixture of D- and L-lactides) is almost quantitative and rapid with catalytic loadings as low as $20 \mathrm{ppm}$.[26] The resulting raclactide is then polymerized into the optically pure poly(L-lactide) and poly(D-lactide) by kinetic resolution.

Epimerization reactions were also followed in the course of the ring-opening polymerization of L-lactide.[27] Among numerous metal oxides, carbonates and carboxylates, antimony, iron and lead oxides, together with tin and bismuth carboxylates led to poly(Llactide) with high optical purity at $120^{\circ} \mathrm{C}$ and various yields. Increasing the temperature to $180^{\circ} \mathrm{C}$ revealed the occurrence of racemization for all systems, the lesser extent being observed for tin and antimony oxides.

As matter of fact, epimerization can be both a powerful tool for polymer chemists or an undesirable side reaction leading to a decrease of the optical purity of polylactide, that has consequences on its thermal properties. Epimerization reactions were reported / studied so far on the lactide monomer or in the course of a ring-opening polymerization reaction. To the best of our knowledge, it was never reported starting from the polymer as the substrate in the absence of the lactide monomer, which may have some potentialities for microstructural control if the extent is high enough. We report in this contribution the epimerization of polylactides in the presence of an organic base, TBD. 


\section{Materials and Methods}

\subsection{Materials}

Poly(L-lactide) was kindly supplied by Corbion (L105). 1,5,7-Triazabicyclo[4.4.0]dec-5ene (TBD) was purchased from Aldrich. Toluene (Aldrich) was purified through alumina column (Mbraun SPS). D-lactide (Purasorb® D) and rac-lactide (Purasorb® D,L) both with an optical purity $>99.5 \%\left(\mathrm{MW}=144 \mathrm{~g} \cdot \mathrm{mol}^{-1}\right.$, free acid $<1 \mathrm{meq} \cdot \mathrm{kg}^{-1}$, water content $\left.<0.02 \%\right)$ were supplied by Purac Biochem BV (The Netherlands) and stored in a glove box under nitrogen atmosphere. Tin(II) 2-ethylhexanoate $\left(\mathrm{Sn}(\mathrm{Oct})_{2}, 95 \%, \mathrm{MW}=405 \mathrm{~g} \cdot \mathrm{mol}^{-1}\right.$, from Sigma-Aldrich (now Merck)) and 1,4-butanediol (> 98\%, Kosher) were stocked in a cold room $\left(\mathrm{T}=4^{\circ} \mathrm{C}\right)$ and used as received.

\subsection{Synthesis of polylactides}

Both D-lactide and rac-lactide ring-opening polymerizations were butanediol initiated and $\operatorname{Sn}(\text { Oct })_{2}$ catalysed $\left([\mathrm{M}]_{0}:[\mathrm{In}]=243: 1 \mathrm{~mol} / \mathrm{mol}\right.$ and $\left.[\mathrm{M}]_{0}:[\mathrm{Cat}]=10000: 1 \mathrm{~mol} / \mathrm{mol}\right)$, and performed in bulk, using Autoclave ${ }^{\mathrm{TM}}$ reactors (Autoclave, France (now Maximator)) at the conditions described before.[28] Yield, 88 - 95\%. ${ }^{1} \mathrm{H} \mathrm{NMR},\left(500 \mathrm{MHz}, \mathrm{CDCl}_{3}, \delta\right): 5.18$ (q, 1H, $\mathrm{CH}), 1.54\left(\mathrm{~d}, 3 \mathrm{H}, \mathrm{CH}_{3}\right)$.

\subsection{Typical epimerization reactions}

Polylactide (0.5 g - $6.94 \mathrm{mmol}$ considering a $72 \mathrm{~g} / \mathrm{mol}$ repeating unit) and TBD (9.7 $\mathrm{mg}, 69.4 \mu \mathrm{mol}$ ) were weighted in a Schlenk flask and dried under vacuum during $6 \mathrm{~h}$. Purified toluene is then added under argon atmosphere. The reaction was carried out at $105^{\circ} \mathrm{C}$ during a certain time. At the end of the reaction, the solution was either (i) precipitated in ethanol and the product was filtered and dried for 48 hours or for low molecular weight polylactides (ii) put under vacuum to remove toluene. 
NMR tube reaction: a NMR tube fitted with a J. Youngs Teflon valve was prepared under inert atmosphere in the glove box with poly(L-lactide) (dried overnight under vacuum), $5 \mathrm{~mol} \%$ TBD and distilled toluene- $\mathrm{d}_{8}$. The reaction was conducted in the NMR tube $48 \mathrm{~h}$ at 105 ${ }^{\circ} \mathrm{C}$.

\subsection{Characterization}

${ }^{1} \mathrm{H},{ }^{13} \mathrm{C}, 2 \mathrm{D}$ COSY, 2D HMQC (Heteronuclear Multiple-Quantum Correlation) NMR spectra were recorded on AVANCE III HD 300 Bruker spectrometer (7.1 Tesla) or Bruker 500 $\mathrm{MHz}$ (for poly(D-lactide) and poly $\left(\right.$ rac-lactide)) at room temperature with $\mathrm{CDCl}_{3}(0.5 \mathrm{~mL})$. Homonuclear decoupled ${ }^{1} \mathrm{H}$ NMR and DOSY spectra were recorded on Avance II 400 Bruker spectrometer (9.4 Tesla) regulated at $298 \mathrm{~K}$ respectively in $\mathrm{CDCl}_{3}$ and toluene $\mathrm{d}_{8}$. The coupling effect between the methine and the $\mathrm{CH}_{3}$ proton of polylactide was removed by irradiation of $\mathrm{CH}_{3}$ area $(1.58 \mathrm{ppm})$ under $\mathrm{O}_{2}(635 \mathrm{~Hz}, \mathrm{PLW} 24=0.0006 \mathrm{Watt})$.

The number-average molecular weights $\left(M_{\mathrm{n}}\right)$ and the molar mass dispersities $(\bigoplus)$ were determined by Size Exclusion Chromatography (SEC). The SEC apparatus (Agilent Technologies) is equipped with Styragel HR1, HR3 and HR4 columns, a refractive index detector and the calibration is done using polystyrene (PS) standards in THF as the eluent (1 $\mathrm{mL} / \mathrm{min}, 40^{\circ} \mathrm{C}$ ). A correction factor of 0.58 is applied to get the $M_{\mathrm{n}}$ of polylactide.[29]

Polarimetry measurements were performed on Perkin Elmer (343) in chloroform $(0.020 \mathrm{~g}$ of polylactide in $2 \mathrm{~mL}$ of solvent) at $\mathrm{T}=20^{\circ} \mathrm{C}$ with the D-line of the sodium lamp $(\lambda=598 \mathrm{~nm})$. The equation 1 (from Biot law) was used to calculate the specific optical rotation from experimental data.

Equation 1: $[a]_{D}^{20}=\frac{a \text { obs }}{\mathrm{C} * \mathrm{l}}$ 
where $\alpha_{\mathrm{obs}}$ is the observed optical rotation angle, $\mathrm{c}$ the concentration of the solution $(\mathrm{g} / \mathrm{mL})$, and 1 the length of the tube in decimeters

The percentage of isomers D was obtained from equation 2.[30]

Equation 2: D $(\%)=\frac{\left([a]_{D}^{20}\right) \text { PLLA }-\left([a]_{D}^{20}\right) \text { PLA after reaction }}{2 *\left([a]_{D}^{20}\right) \text { PLLA }} \times 100$

The measurement of poly(L-lactide) optical rotation angle $\left(\alpha_{\mathrm{obs}}\right)$ was carried out eight times and the calculated specific optical rotation values varied from $-159^{\circ}$ to $-165^{\circ}$ with an average of $-162.3^{\circ}\left(\right.$ standard deviation $\left.=2.3^{\circ}\right)$. This corresponds to a standard deviation on the epimerization rate $(\mathrm{D} \%)$ of $0.6 \%$. This average specific rotation was in agreement with the value of the literature [31] (chloroform, $25{ }^{\circ} \mathrm{C}, \lambda=598 \mathrm{~nm}$ ). Other values are an average over 3 measurements.

Differential Scanning Calorimetry (DSC) experiments were carried out on a DSC Q20 instrument calibrated according to standard procedures using a high purity Indium sample. For the analyses, samples $(3 \mathrm{mg})$ were placed into aluminum pans, heated from $0^{\circ} \mathrm{C}$ to $195^{\circ} \mathrm{C}$, cooled to $195^{\circ} \mathrm{C}$ from $0{ }^{\circ} \mathrm{C}$ and heated again from $0{ }^{\circ} \mathrm{C}$ to $195{ }^{\circ} \mathrm{C}$ at a rate of $10^{\circ} \mathrm{C} / \mathrm{min}$ under nitrogen atmosphere.

Positive-ion Matrix assisted LASER Desorption/Ionization-Mass Spectrometry (MALDIMS) experiments were performed using a Waters QToF Premier mass spectrometer equipped with a Nd:YAG laser operating at $355 \mathrm{~nm}$ (third harmonic) with a maximum output of $65 \mu \mathrm{J}$ delivered to the sample in $2.2 \mathrm{~ns}$ pulses at $50 \mathrm{~Hz}$ repeating rate. Time-of-flight mass analysis was performed in the reflectron mode at a resolution of about $10 \mathrm{k}(\mathrm{m} / \mathrm{z} 569)$. All samples were analyzed using trans-2-[3-(4-tert-butylphenyl)-2-methylprop-2-enylidene]malononitrile (DCTB) as a matrix. Polymer samples were dissolved in THF to obtain $1 \mathrm{mg} \cdot \mathrm{mL}^{-1}$ solution. 
Additionally, $40 \mu \mathrm{L}$ of $2 \mathrm{mg} \cdot \mathrm{mL}^{-1} \mathrm{NaI}$ solution in acetonitrile was added to the polymer solution.

The polylactide obtained after reaction in the NMR tube was dried under vacuum within the glove box to remove toluene $\mathrm{d}_{8}$ (even though traces of solvent remind trapped in the viscous product as evidenced by the $v(C D)$ stretching bands between 2000 and $2200 \mathrm{~cm}^{-1}$ ) The sample was then diluted in dry $\mathrm{KBr}$ and loaded under inert atmosphere into an air-tight DRIFT cell equipped with $\mathrm{CaF}_{2}$ windows. Diffuse reflectance infrared spectra were collected in a Nicolet 6700 FT-IR spectrophotometer in $4 \mathrm{~cm}^{-1}$ resolution and the final spectra comprise 32 scans.

\section{Results and discussion}

\subsection{Epimerization}

After assessing several solvents and temperatures, the reactions were conducted using poly(L-lactide) as the substrate and $1 \mathrm{~mol} \% \mathrm{TBD}$ in toluene at $105^{\circ} \mathrm{C}$. Representative examples are given in Table 1, entries 2-8, and can be compared to a blank experiment conducted without catalyst (entry 1). The recovering yield was found to be higher than $95 \%$ in all cases. Substantial racemization of poly(L-lactide) is observed in these conditions, with up to $c a$. $30 \% \mathrm{D}$ stereoisomer at the equilibrium. It is noteworthy that the number-average molecular weight of the resulting polylactide is lower than that of the starting material. From the evolution of the molecular weight and the amount of D stereoisomer over time, one can see that racemization and chain scission are occurring simultaneously. The final number-average molecular weight is reached after $16 \mathrm{~h}$, while the racemization continues to proceed until $c a .48 \mathrm{~h}$ reaction time.

Base catalyzed epimerization of $\alpha$-alkyl carboxylic acid derivatives is well known in the literature.[32] It can occur via two mechanisms represented Scheme 2. The first step is the abstraction of the acidic proton in $\alpha$ of the carbonyl group by the base to form a carbanion. The 
latter can recombine with the proton, or go through a tautomer, the enolate form, both leading to the inversion.

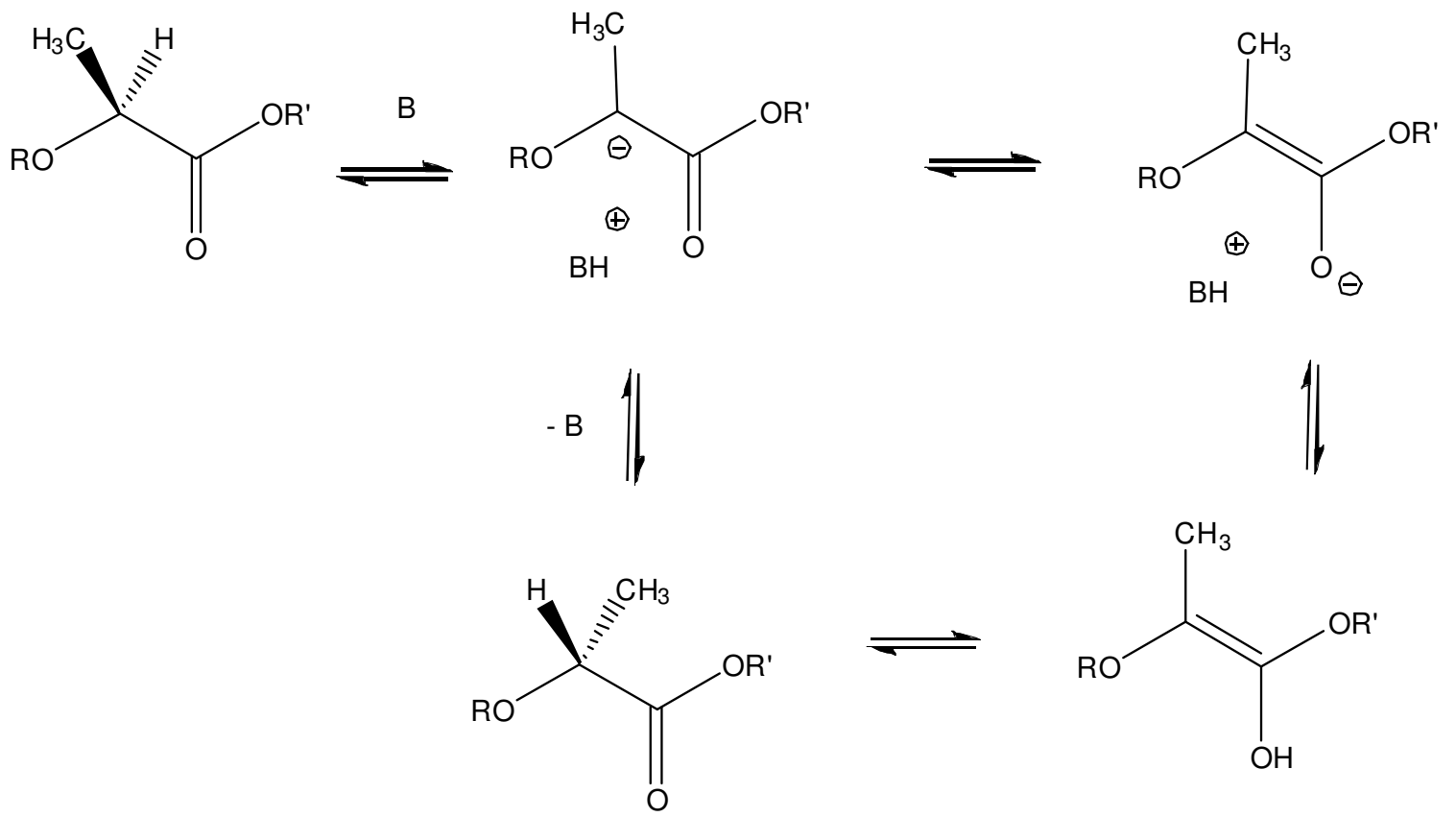

Scheme 2 Epimerization mechanism 
Table 1

Epimerization of poly(L-lactide) in the presence of TBD

\begin{tabular}{|c|c|c|c|c|c|c|}
\hline Entry $^{a}$ & $\begin{array}{l}\text { Time } \\
\text { (hours) }\end{array}$ & $\begin{array}{l}\text { Catalyst } \\
\text { loading } \\
(\mathrm{mol} \%)\end{array}$ & {$[a]_{D}^{20}\left(^{\circ}\right)^{\mathrm{b}}$} & $D(\%)^{c}$ & $\begin{array}{c}M_{\mathrm{n}} \\
\text { corrected } \\
(\mathrm{g} / \mathrm{mol})^{d}\end{array}$ & $\bigoplus^{d}$ \\
\hline \multicolumn{2}{|c|}{ Starting material } & - & -162.3 & 0 & 35400 & 1.7 \\
\hline 1 & 48 & - & -159.4 & 0.9 & 32500 & 1.8 \\
\hline 2 & 1 & 1 & -128.9 & 10.3 & 9100 & 2.4 \\
\hline 3 & 6 & 1 & -124.3 & 11.7 & 8700 & 1.9 \\
\hline 4 & 16 & 1 & -98.7 & 19.6 & 5900 & 1.8 \\
\hline 5 & 24 & 1 & -90.6 & 22.1 & 5800 & 1.7 \\
\hline 6 & 48 & 1 & -64.9 & 30.0 & 5900 & 1.6 \\
\hline 7 & 120 & 1 & -61.7 & 31.0 & 5800 & 1.5 \\
\hline 8 & 240 & 1 & -59.5 & 31.7 & 5900 & 1.5 \\
\hline 9 & 48 & 3 & -22.4 & 43.1 & 1900 & 1.7 \\
\hline 10 & 48 & 5 & -13.3 & 45.9 & 1500 & 1.9 \\
\hline 11 & 240 & 0.5 & -111 & 15.9 & 8900 & 1.9 \\
\hline 12 & 240 & 0.25 & -125 & 12.0 & 12600 & 1.9 \\
\hline
\end{tabular}

${ }^{\text {a }} 1 \mathrm{~mol} \%$ of catalyst, $0.5 \mathrm{~g}$ poly(L-lactide $)(2.3 \mathrm{~mol} / \mathrm{L}), \mathrm{T}=105^{\circ} \mathrm{C}$, anhydrous toluene $(3$ $\mathrm{mL})$.

b Specific optical rotation determined by polarimetry (chloroform, $20^{\circ} \mathrm{C}, \lambda=598 \mathrm{~nm}$, standard deviation $\pm 2.5^{\circ}$ ) 
${ }^{\mathrm{c}}$ Determined with equation $2($ standard deviation $\pm 0.6 \%) ; \mathrm{d}: M_{\mathrm{n}}$ corrected $=M_{\mathrm{n}}$ SEC $*$ 0.58 and molar mass dispersity
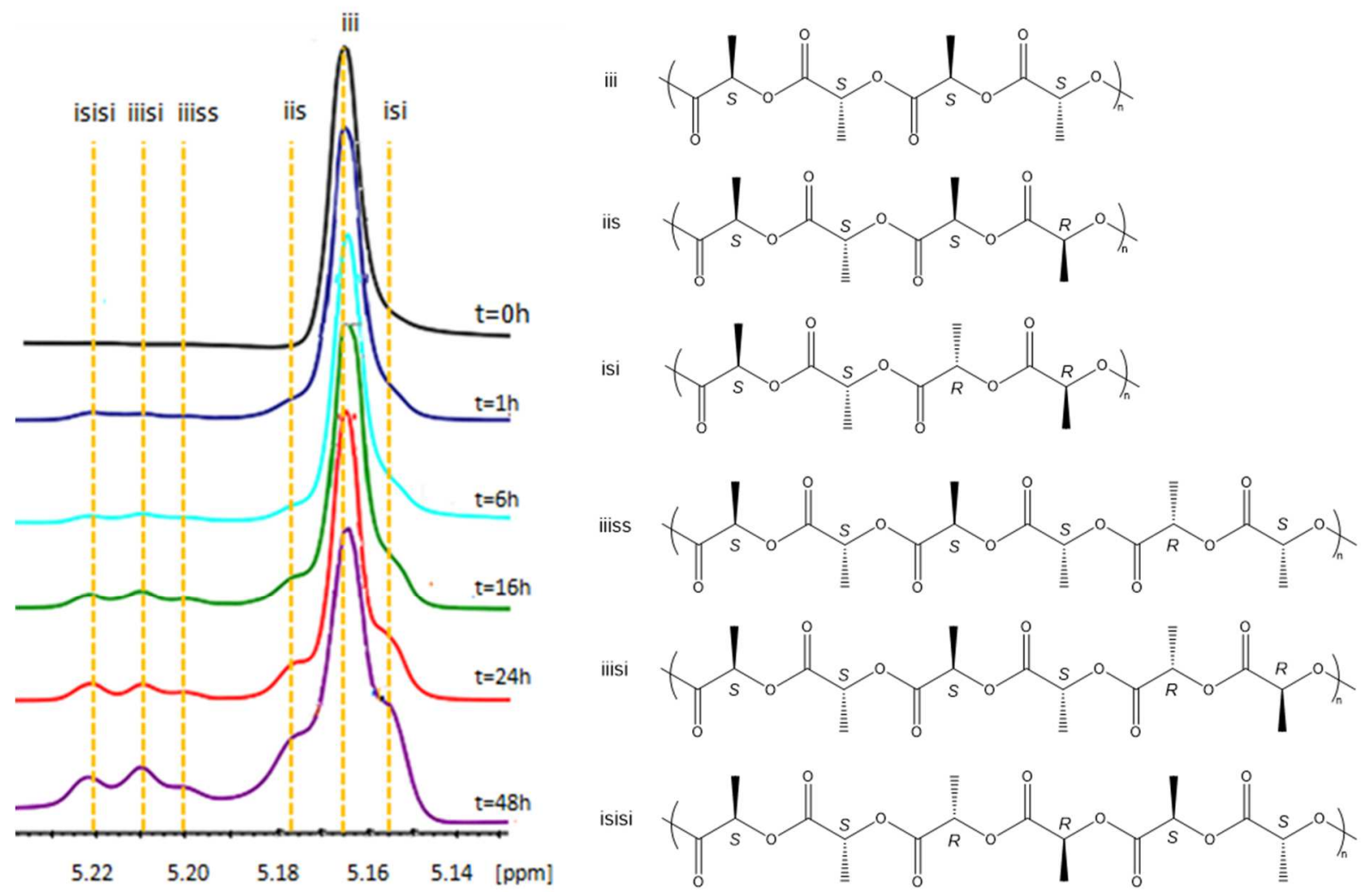

Fig. 1. ${ }^{1} \mathrm{H}$ Homonuclear decoupled NMR of polylactide as a function of the reaction time and related tetrads and hexads.

${ }^{1} \mathrm{H}$ NMR spectroscopy is a powerful tool to analyze the fine structure of organic compounds. However, in the case of closely related structure the scalar coupling between proton often leads to signal overlaps hampering a precise attribution. In this sense, homonuclear decoupling allows to obtain a simpler spectrum devoid of mutiplet facilitating their interpretation. The microstructure of the resulting polylactide was thus further studied by homonuclear decoupled ${ }^{1} \mathrm{H}$ NMR spectroscopy. Typical NMR spectra are presented Fig.1. The iii tetrad of poly(L-lactide) evolves as a function of the reaction time toward a more complex 
microstructure. Hexads stereosequences involving the sis and iis/sii tetrads are resolved in homonuclear decoupled ${ }^{1} \mathrm{H}$ NMR of polylactide.[33] The isisi, iiisi and iiiss hexads appear as the reaction proceeds. The latter iiiss sequence can be found in polylactide synthesized in the absence of transesterification as soon as meso-lactide is involved[33] but is absent in samples resulting from the polymerization of L- and/or D-lactide.

This microstructure may be the result of both epimerization and transesterification occurring in the presence of TBD. MALDI analyses (reported in the appendix) could not be conclusive about the latter, as the MALDI ToF mass spectra of the poly(L-lactide) precursor (represented Fig. A.1) shows already macromolecules with both odd and even multiple of 72 , as a confirmation of transesterification reactions occurring during the production step. Bases such as TBD are however known to catalyze transesterification reactions,[34] (ring-opening polymerization being itself a transesterification) and the occurrence of transesterification in toluene at $105^{\circ} \mathrm{C}$ is thus highly probable.

We further assessed the influence of the TBD loading on the reaction. The molecular weight of the resulting polylactide follows the catalytic loading as shown entries 9-10 for 3 and $5 \mathrm{~mol} \%$ but also for lower amount, given in entries 11 and 12. Besides chain scission, the extent of racemization is also a function of the TBD loading, with up to $46 \% \mathrm{D}$ stereoisomer in the resulting polymer for $5 \mathrm{~mol} \%$ TBD (entry 10 ), i.e close to the amount of a polymer obtained from the ring-opening polymerization of rac-lactide. This relationship is interesting as it allows one to control or target a specific amount of D stereoisomer in the microstructure, at the expense of the molecular weight however. We further assessed the kinetic of the reaction for low loadings (Fig. 2). The time to reach (i) the final number-average molecular weight and (ii) the final D stereoisomer content are decreasing with increasing catalytic loading. Again, it can be seen that the microstructure of the resulting polylactide can be controlled in a certain range of 
D stereoisomer content (0 to $18 \%$ ) and molecular weight (24 000 to $9000 \mathrm{~g} / \mathrm{mol}$ ), but not independently: the higher the $\mathrm{D} \%$, the lower the number-average molecular weight.
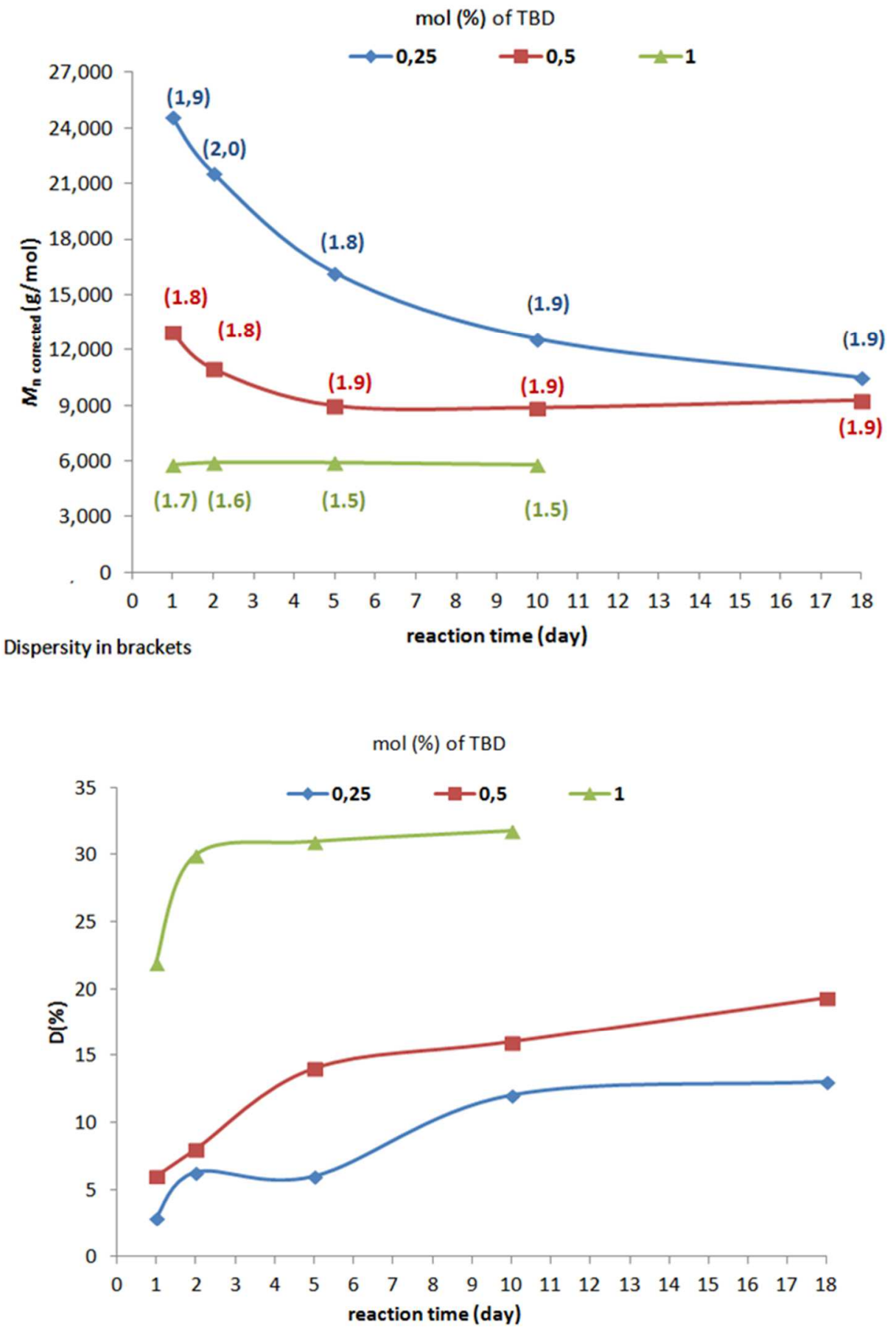

Fig. 2. Effect of catalyst loading on the molecular weight (top) and the amount of Dstereoisomer (bottom) 


\subsection{Chain scission mechanism}

The extent of chain scission, i.e a number-average molecular weight decreasing with increasing quantities of TBD may suggest a nucleophilic attack of the latter on the carbonyl moieties along the macromolecular chain, as presented in Scheme 3. Although the basic character of guanidines such as TBD usually control their reactivity, they can also act as nucleophiles. [9] [35] [36] [37] In this case, TBD end-capped polylactide should be formed during the reaction. MALDI ToF analyses (Fig. A.1) revealed carboxylic acid terminated linear polylactide and a small amount of macrocyclic polylactide, but not the expected TBD endcapped macromolecule. It is however known that the acyl-TBD bond is very reactive toward protonated compounds, reacting quantitatively with $e . g$ alcohols in less than 10 minutes at room temperature.[37] The acyl-TBD bond, if formed during the reaction, may thus be hydrolyzed upon quench, and no longer be detectable by analytical techniques after this step.

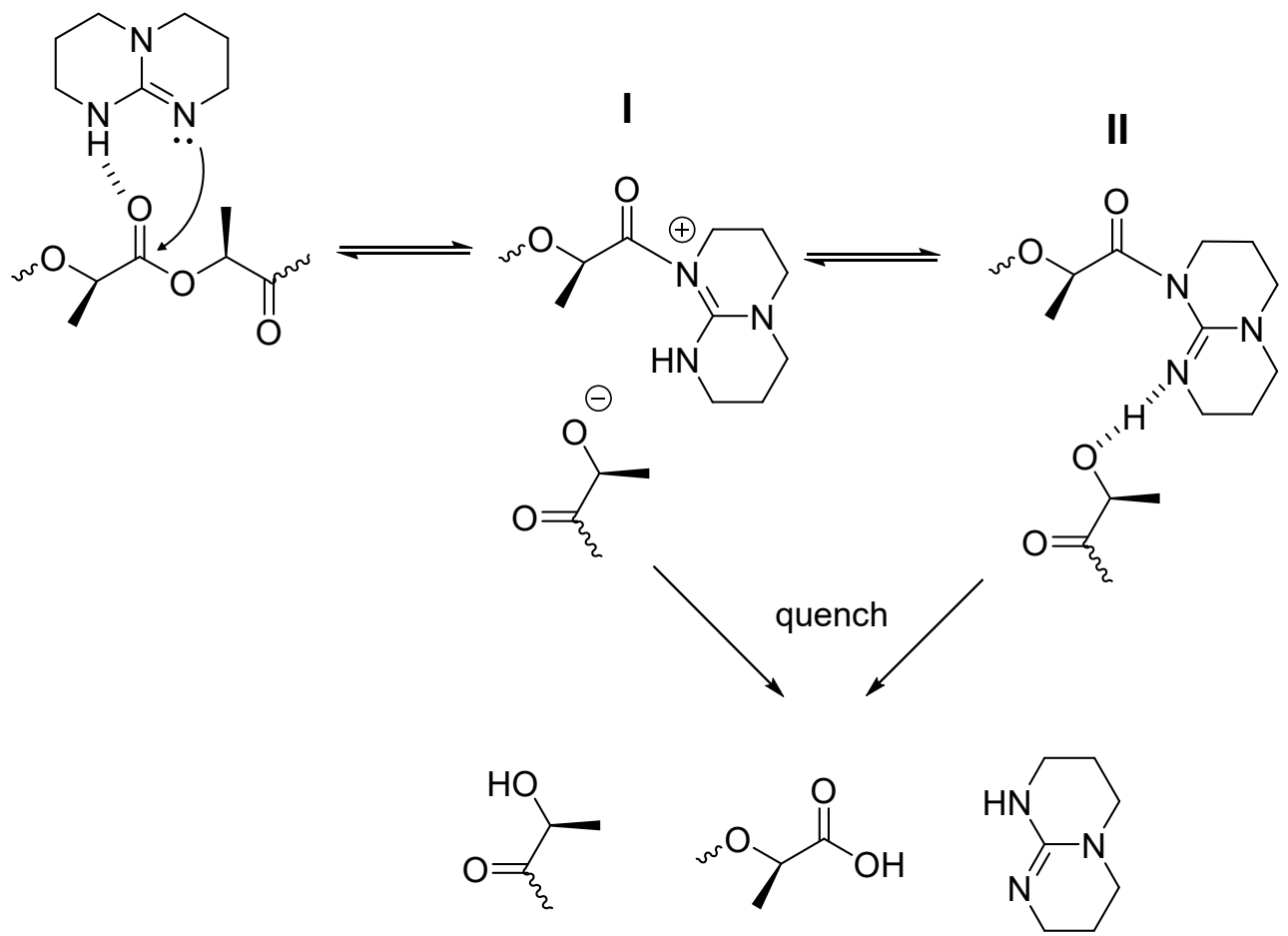

Scheme 3. Proposed mechanism for the chain scission and hydrolysis of the resulting acyl-TBD upon quench 


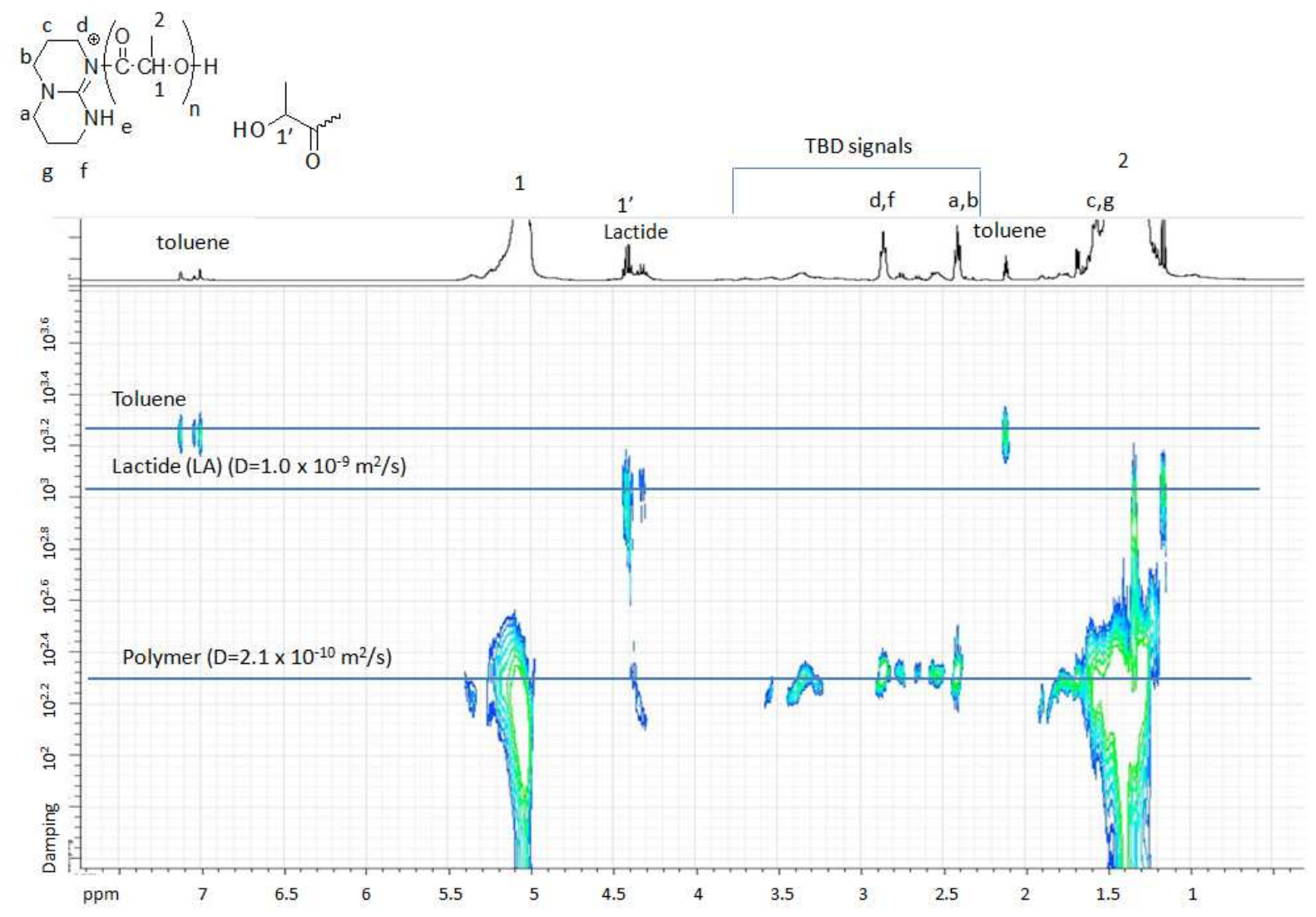

Fig. 3. DOSY analysis of an experiment conducted in an NMR tube with 5 mol\% TBD

We thus performed a reaction in a sealed NMR tube prepared in the glovebox to check if the acyl-TBD species is formed during the reaction. A loading of $5 \mathrm{~mol} \%$ was chosen for this specific experiment in order to have a quantity of N-heterocycle high enough to conduct a reliable DOSY NMR study, that is shown Fig. $3 .{ }^{1} \mathrm{H}$ NMR signals assignments were done on the basis of COSY, ${ }^{13} \mathrm{C}$ and HSQC analyses that are provided in the SI section (Fig. A.2 - Fig. A.5). The measurement of the diffusion coefficient allows to check if a molecule is covalently bonded to the polymer. Indeed, if this is the case, they will have the same diffusion coefficient, while if not, two diffusion coefficients will be detected. It can be seen Fig. 3 that the signals representative of the TBD moieties are at the same level than those of the polylactide. The diffusion coefficient is found around $2.110^{-10} \mathrm{~m}^{2} . \mathrm{s}^{-1}$, while that of the native TBD molecule was determined at $1.310^{-9} \mathrm{~m}^{2} . \mathrm{s}^{-1}$ (see Fig. A.6), well below. This confirms the existence of a bond between the TBD moiety and the polylactide at the end of the reaction. It can also be seen 
that the ${ }^{1} \mathrm{H}$ NMR signals resulting from the TBD are shifted after the reaction compared to the initial TBD (Fig. A.6). A small amount of lactide is also formed in this experiment, which was also observed for entries 9 and 10 where 3 and 5\% catalyst were used. This low quantity was quantified by NMR to $c a$. $1-2 \mathrm{~mol} \%$. This may be attributed to a back-bitting reaction, as proposed in the literature when the pyrolysis of polylactide is realized in the presence of a catalyst at temperatures around $250{ }^{\circ} \mathrm{C}$.[38] [39] The corresponding mechanism adapted from refs [38] [39] is given in the appendix as Scheme A.1.

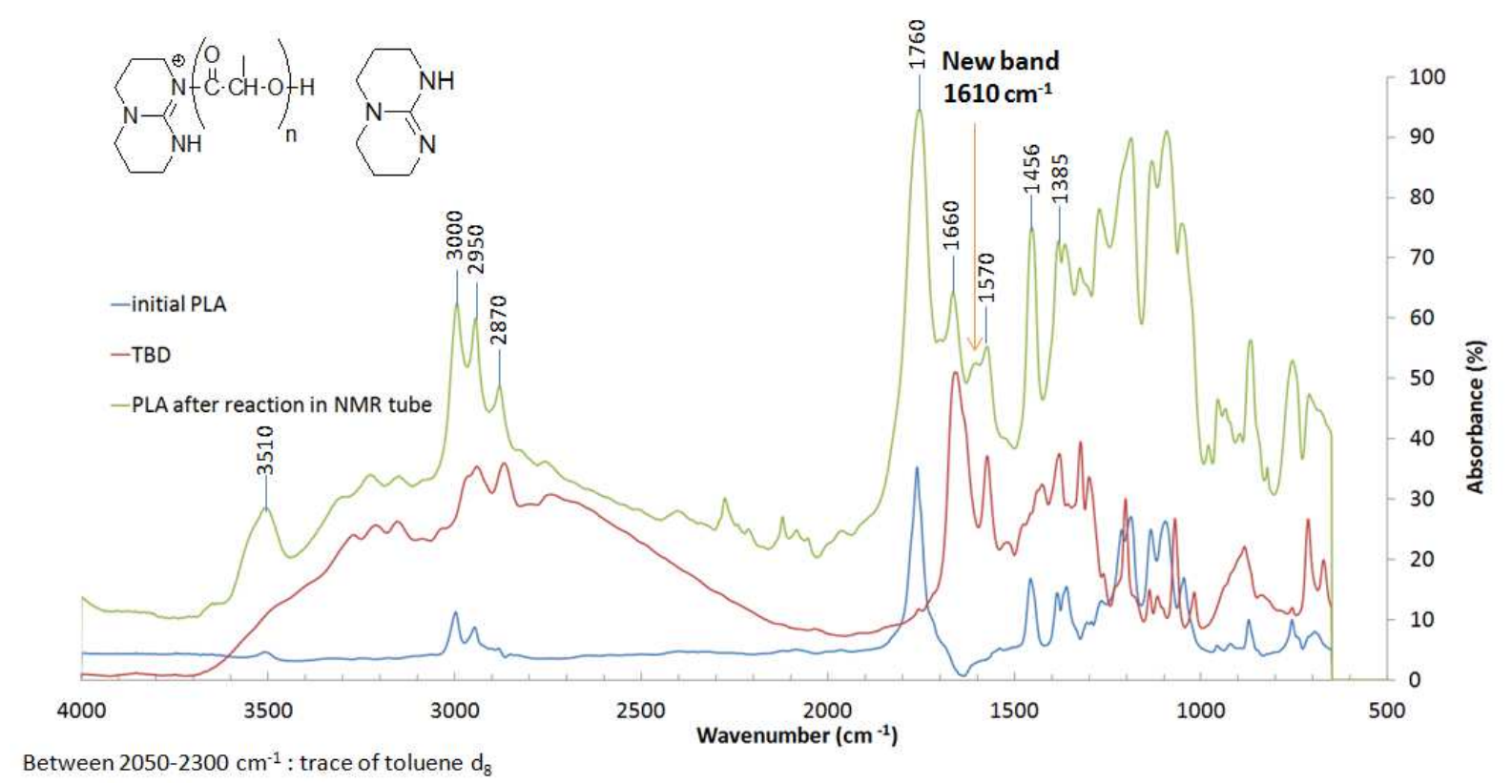

Fig. 4. Infrared spectra of poly(L-lactide), TBD and polylactide after the reaction

Infrared analyses were performed to get additional information about the nature of the polylactide-TBD bond. Fig. 4 shows the infrared spectra of the poly(L-lactide) precursor, TBD and the product of the reaction conducted under inert atmosphere in the NMR tube. Polylactide characteristic stretching frequencies for $v(C=O)$ and $v(C-O)$ can be seen at $1760 \mathrm{~cm}^{-1}$ and between 1000 and $1300 \mathrm{~cm}^{-1}$ together with the stretching frequencies for $\mathrm{v}_{\mathrm{s}}\left(\mathrm{CH}_{3}\right)$ and $\mathrm{v}_{\mathrm{as}}\left(\mathrm{CH}_{3}\right)$ at 2950 and $3000 \mathrm{~cm}^{-1}$, respectively. The peaks of $\delta_{\mathrm{s}}\left(\mathrm{CH}_{3}\right)$ and $\delta_{\text {as }}\left(\mathrm{CH}_{3}\right)$ were identified at 1385 and $1456 \mathrm{~cm}^{-1}$. The signal of alcohol $\mathrm{v}(\mathrm{OH})$ polylactide chain end was observed at $3510 \mathrm{~cm}^{-1}$. 
Regarding TBD, stretching frequencies for $v(C=N)$ and $v(C-N)$ are visible at $1660 \mathrm{~cm}^{-1}$ and between $1000-1300 \mathrm{~cm}^{-1}$. The amine function can be seen at $1570 \mathrm{~cm}^{-1}(\delta(\mathrm{NH}))$ and $3200-3300$ $\mathrm{cm}^{-1}(\mathrm{v}(\mathrm{NH}))$ while $\delta\left(\mathrm{CH}_{2}\right), v_{\mathrm{s}}\left(\mathrm{CH}_{2}\right)$ and $v_{\text {as }}\left(\mathrm{CH}_{2}\right)$ can be seen between $1300-1500 \mathrm{~cm}^{-1}$, at 2870 and $2950 \mathrm{~cm}^{-1}$, respectively. On the infrared spectrum of the reaction product after reaction, peaks characteristics of both TBD and polylactide were observed, together with the apparition of a new peak at $1610 \mathrm{~cm}^{-1}$. This latter peak is in the range of a $v(\mathrm{~N}-\mathrm{CO})$ that may result from a nucleophilic attack of TBD on a polylactide ester group.

In summary, the mechanism represented Scheme 3 may operate for the chain scission. The first step would be a nucleophilic attack of TBD on an activated carbonyl moiety, resulting in the acylguanidinium intermediate I. The latter may be in equilibrium with II in the course of the reaction, and the acyl-TBD bond may finally be hydrolyzed at the quenching step, releasing polylactide and TBD.

\subsection{Thermal properties}

The samples obtained with $1 \mathrm{~mol} \%$ TBD were subjected to DSC analyses represented Fig. 5. Decrease of (i) the glass transition temperature $\mathrm{Tg}$ from $61^{\circ} \mathrm{C}$ to $51^{\circ} \mathrm{C}$, (ii) the melting temperature from $177{ }^{\circ} \mathrm{C}$ to $136{ }^{\circ} \mathrm{C}$ and (iii) the crystalline ratio from $56 \%$ to $8 \%$ are observed as a function of the reaction time. For a content of $30 \%$ of the D stereoisomer, there was almost no crystallinity on the first heating (crystalline ratio $\chi \mathrm{c}=8 \%$ ).

In addition of the influence of the $\mathrm{D}$ stereoisomer content, the discussion on the influence of the microstructure on the glass transition temperature has to consider the molecular weight, as the $\mathrm{Tg}$ is dependent on the latter in this range. For $16 \mathrm{~h}$ and $48 \mathrm{~h}$ reaction time (entries 4 and 6), the final number-average molecular has been reached. The increase of the percentage of the D stereoisomer from $\mathrm{ca}$. 20 to $30 \%$ leads to a $\mathrm{Tg}$ decreases from $52.3{ }^{\circ} \mathrm{C}$ to $51.3{ }^{\circ} \mathrm{C}$ in first heating and $51.8^{\circ} \mathrm{C} v s .48 .1^{\circ} \mathrm{C}$ in the second heating. This evolution is in agreement with 
the one observed in the literature for polylactides with different optical purity obtained by ringopening copolymerization of D- and L-lactides using tin octanoate as initiaor.[40] The melting temperature and the crystallinity also decrease on our samples, $152.4{ }^{\circ} \mathrm{C}$ vs. $136.6{ }^{\circ} \mathrm{C}$ and $29 \%$ vs. $8 \%$ respectively, which was also observed in the literature on polylactides made by ringopening copolymerization using aluminium SALEN complexes by Spassky and coworkers.[41]

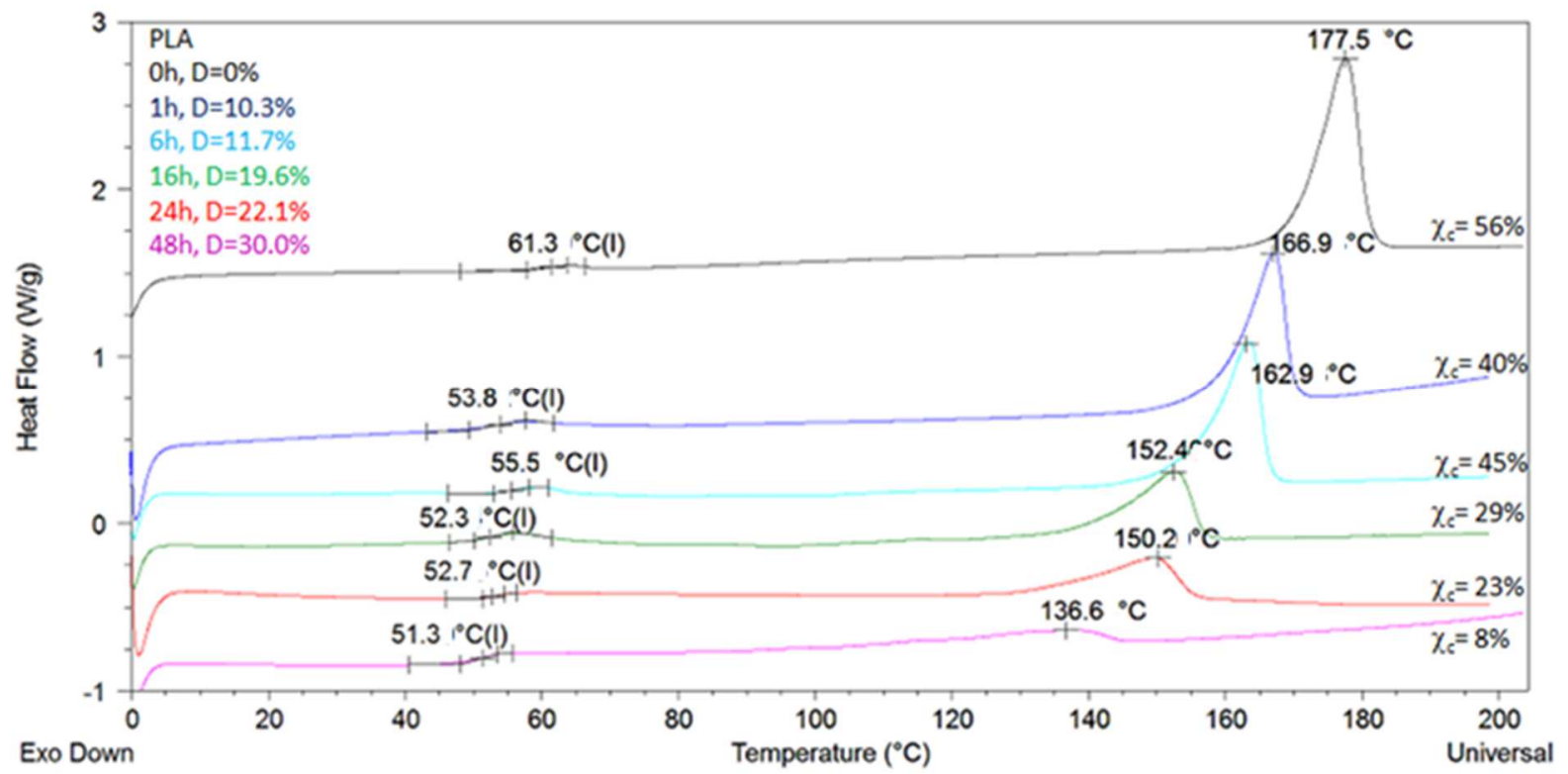

Fig. 5. DSC analysis (first heating). The percentage of crystallinity of the samples was calculated via the following equation $\chi_{c}=\Delta H_{\text {melting }} / \Delta H_{\text {melting }}{ }^{\circ}$ (crystallized PLA) where $\Delta$

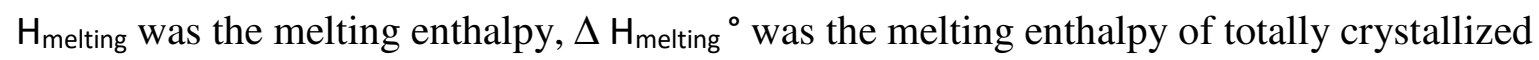
polylactide (93 J/g after [42]).

\subsection{Poly(D-lactide) and Poly(rac-lactide)}

Experiments starting from poly(D-lactide) and poly(rac-lactide) were finally realized to assess the influence of the microstructure and stereoconfiguration of the polylactide precursor on the epimerization reaction. Representative results are given in Table 2. The epimerization rate is slightly higher starting from poly(D-lactide) $v s$. poly(L-lactide), and so is the 
epimerization extent. It is noteworthy that, starting from the poly(rac-lactide), the 50/50 ratio between the $\mathrm{D}$ and L stereoisomer stays almost constant, with a slight increase in $\mathrm{D} \%$. Although in the range of the standard deviation, this could be consistent with an epimerization rate of the same order of magnitude for D- and L-stereocenters, with however a slightly higher rate for the D, as observed on the poly(D-lactide). The study of the origin of this difference by DFT (Density Functional Theory) will be the subject of a forthcoming work.

The different values of the number-average molecular weight obtained for the 3 polylactides considered in this study may be a consequence of the presence of various amount of macrocyclic species. MALDI analysis (reported Fig. A.1 and Fig. A.7) reveals the presence of macrocycles for all polylactides. The nucleophilic attack onto a macrocycle open it and thus leads to a number-average molecular weight higher than the scission of a linear macromolecule of a similar $\mathrm{M}_{\mathrm{n}}$ into two macromolecular chains. In addition, macrocycles have a higher retention time in the SEC apparatus,[43] which will also lead after opening to an increase of the SEC measured molecular weight. The combination of these two factors may explain the difference in number-average molecular observed here under the hypothesis of a different content of macrocycles for the 3 polylactides. 


\section{Table 2}

Reactions conducted with poly(D-lactide) and poly(rac-lactide)

\begin{tabular}{|c|c|c|c|c|c|c|}
\hline Entry $^{\mathrm{a}}$ & Polylactide & $\begin{array}{l}\text { Time } \\
\text { (hours) }\end{array}$ & {$[a]_{D}^{20}\left(^{\circ}\right)^{b}$} & $\mathrm{D}(\%)^{\mathrm{c}}$ & $M_{\mathrm{n} \text { corrected }}(\mathrm{g} / \mathrm{mol})^{\mathrm{d}}$ & $\theta^{d}$ \\
\hline 13 & Poly & 0 & 152.0 & 100 & 29000 & 1.2 \\
\hline 14 & (D-lactide) & 1 & 110.7 & 86.5 & 21500 & 1.3 \\
\hline 15 & & 6 & 88.6 & 79.1 & 4700 & 2.6 \\
\hline 16 & & 24 & 54.6 & 68.0 & 4000 & 1.9 \\
\hline 17 & & 48 & 38.2 & 62.6 & 3800 & 1.7 \\
\hline 18 & & 0 & 0.0 & 50 & 15700 & 1.1 \\
\hline 19 & Poly & 6 & 0.67 & 50.2 & 2900 & 1.7 \\
\hline 20 & (rac-lactide) & 24 & 0.23 & 50.1 & 2800 & 1.7 \\
\hline 21 & & 48 & 1.3 & 50,5 & 2200 & 1.7 \\
\hline
\end{tabular}

${ }^{\mathrm{b}}$ Specific optical rotation determined by polarimetry (chloroform, $20^{\circ} \mathrm{C}, \lambda=598 \mathrm{~nm}$, standard deviation $\pm 2.5^{\circ}$ )

${ }^{\mathrm{c}}$ Determined with equation 2 (standard deviation $\pm 0.6 \%$ ).

${ }^{\mathrm{d}} M_{\mathrm{n}}$ corrected $=M_{\mathrm{n} \mathrm{SEC}} * 0.58$ and dispersity.

\subsection{Implications of the work}

The results of the present study have implications in the field of polymer synthesis, microstructural control and polymer recycling. Regarding polymer synthesis, the results show 
that in the frame of a polymerization experiment, for long reaction time at high temperature, chain scission may occur, and could lead to some deviations of the number-average molecular weight $v s$. the monomer / protic initiator ratio, with the former being lower than the latter. In addition, the production of poly(L-lactide) or poly(D-lactide) using TBD as a catalyst may lead to semi-crystalline polylactides suffering from a loss in the optical properties and a decrease of the melting temperature and ratio.

The reaction reported in this work also enables to access carboxylic acid end-capped oligolactides with targeted molecular weight. Polylactide hydrolysis and ring-opening polymerization of lactide also allow the access to similar end-capped oligolactides with a targeted molecular weight if water is used as a protic source. The strategy developed in this work enables to additionally control the $\mathrm{D} / \mathrm{L}$ stereoisomer ratio of the resulting oligolactide starting from poly(L-lactide) or poly(D-lactide) precursors by playing on the catalyst ratio. The resulting thermal properties of the oligomer / polymer can be tuned in a certain range. Recycling poly(L-lactide) and/ or poly(D-lactide) using TBD in the experimental conditions of this work can afford the access to fully amorphous oligomers starting from a semi-crystalline polymer, which extend the range of applications of the recycled polylactide. It is thus complementary to existing approaches for recycling polylactide into oligomers of controlled molecular weight. The position of the work in the landscape of polylactide chemical recycling is represented in Scheme 4 . 
<smiles>CC(OC(C)(C)C)C(=O)C(C)(C)C</smiles>

Lactides including optical pure / higher cyclic oligomers / byproducts<smiles>CC(OC(C)(C)C)C(=O)C(C)(C)C</smiles>

Organic base

In solution

This work<smiles>CC(OC(C)(C)C)C(=O)C(C)(C)C</smiles>

$\mathrm{ROH} /$ Catalyst

$\longrightarrow$ Alkyl lactates, lactic acid, oligomers

Alcoholysis

Hydrolysis

Scheme 4. Pyrolysis,[38] [39] [44] [45] alcoholysis, [22] [23] [46] [47] hydrolysis[48] [49]

[50] and the current work in the landscape of chemical recycling of polylactide.

\section{Conclusion}

The reactions induced by TBD on polylactide in solution have been studied. Epimerization and chain scission are observed at $105^{\circ} \mathrm{C}$ in toluene. It is proposed that the latter occurs via a nucleophilic attack of the catalyst, leading to a TBD end-capped oligolactide that is hydrolyzed upon quench. The molecular weight of the resulting oligomers, terminated by a carboxylic acid moiety, can be controlled by adjusting the catalyst / lactate units ratio, with dispersities around 1.5-1.6. In the presence of $1 \% \mathrm{TBD}$, the epimerization leads to the presence of $c a .30 \%$ D-stereoisomer starting from poly(L-lactide), while up to $38 \%$ L-stereoisomer are obtained starting from poly(D-lactide) in similar conditions. The epimerization rate of D-lactate units is thus slightly higher than that of L-lactate units. The amount of D-lactate $v s$. L-lactate of 
poly(rac-lactide) is as a consequence negligibly affected by the nitrogeneous base, due to equilibrium between the epimerization of both species.

\section{Acknowledgments}

This work was funded by the FWV ALPO Interreg Grant and the authors thanks the European Regional Development Fund (FEDER) and the University of Lille. Chevreul Institute (FR 2638), Ministère de l'Enseignement Supérieur de la Recherche et de l'Innovation, Région Hauts de France are also acknowledged for supporting and funding partially this work. The authors are gratefully acknowledged to Aurélie Malfait and Jonathan Potier for SEC measurements. The UMONS MS laboratory acknowledges the Fonds National de la Recherche Scientifique (F.R.S.-F.N.R.S.) for its contribution to the acquisition of the Waters QToF Premier mass spectrometer and for continuing support. 


\section{Appendix}

Fig. A.1 MALDI data for the poly(L-lactide) precursor (in red) and the PLAs obtained after 6h (entry 3, purple) and 24h (entry 5, brown) reaction time
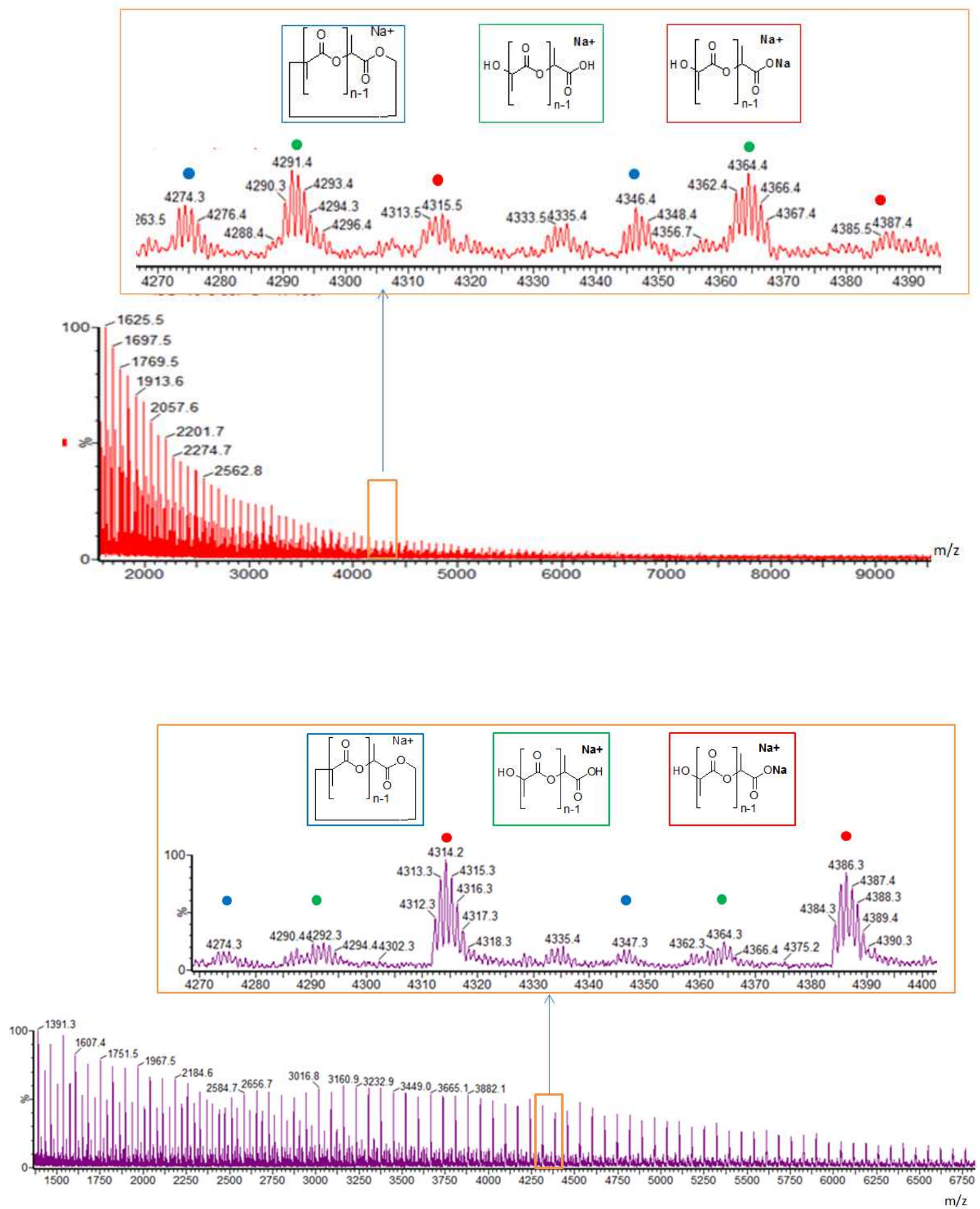


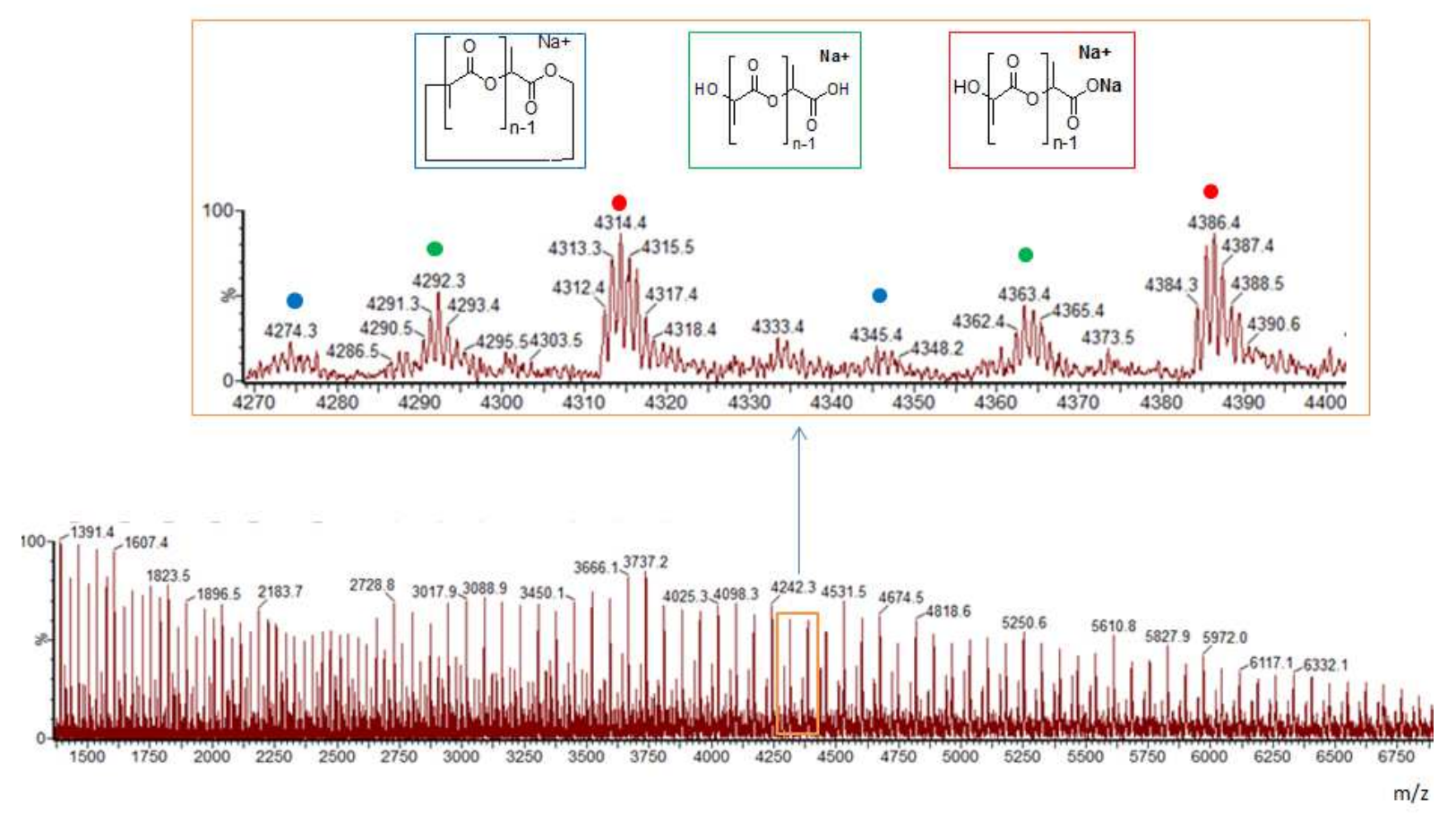

Fig. A.2 Comparison of ${ }^{1} \mathrm{H}$ NMR spectra (toluene $\mathrm{d}_{8}, 400 \mathrm{MHz}$ ) of TBD and the PLA obtained after reaction in NMR tube. 
TBD

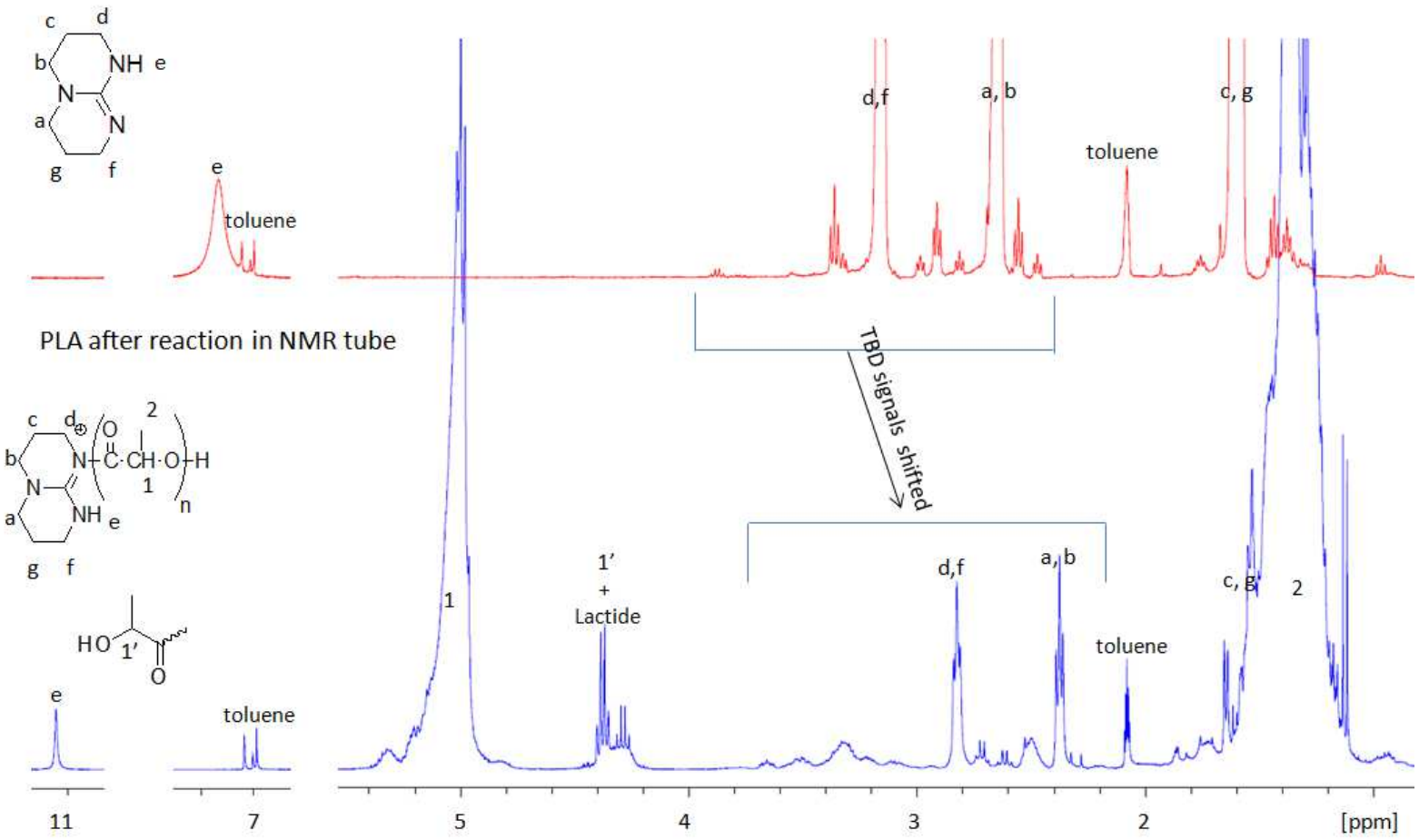


Fig. A.3 COSY NMR spectrum of PLA after reaction in NMR tube (toluene $\mathrm{d}_{8}, 400 \mathrm{MHz}$ )

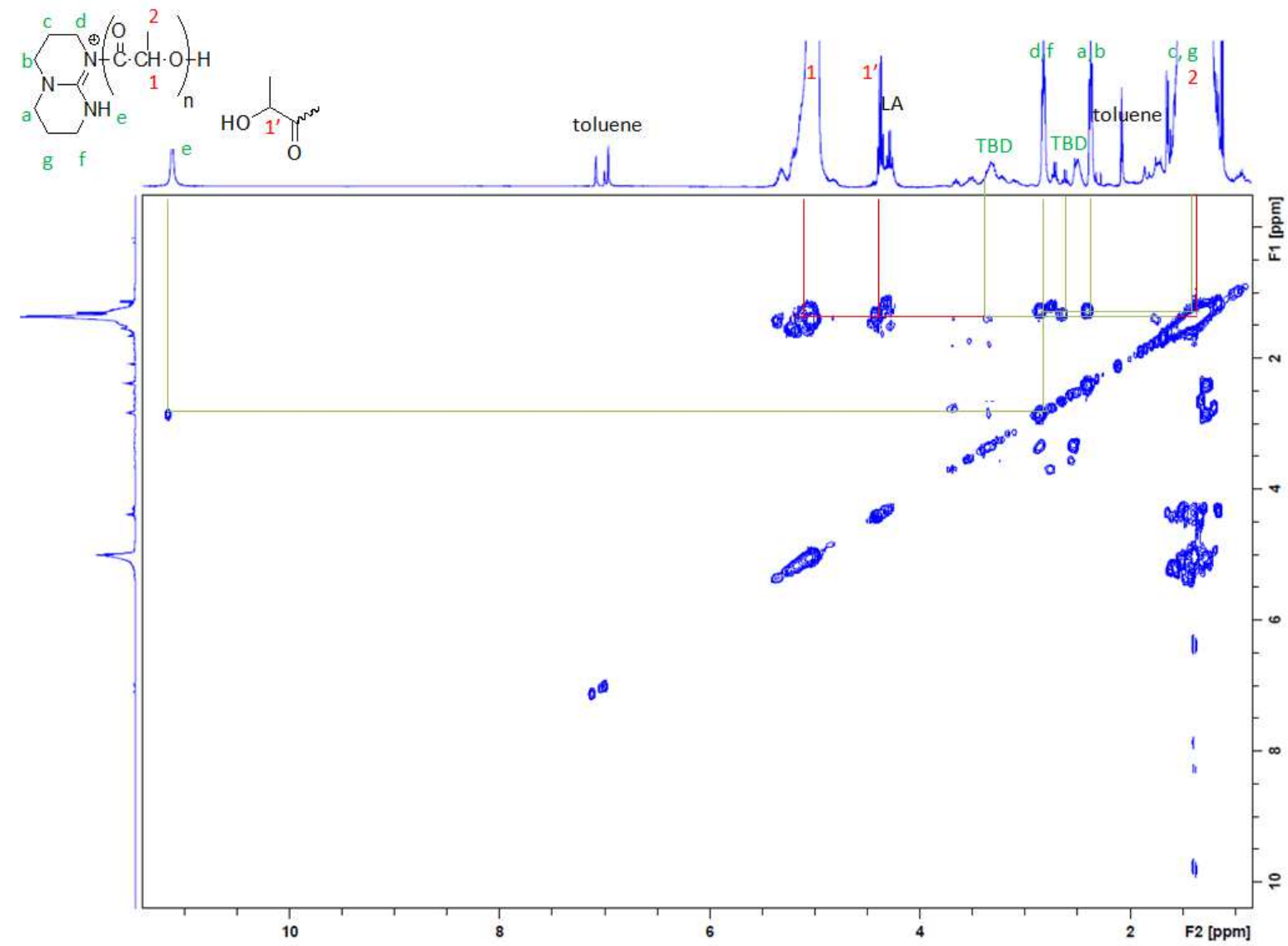


Fig. A.4 ${ }^{13} \mathrm{C}$ NMR spectra of TBD and PLA after reaction in NMR tube (toluene $\mathrm{d}_{8}, 400 \mathrm{MHz}$ )

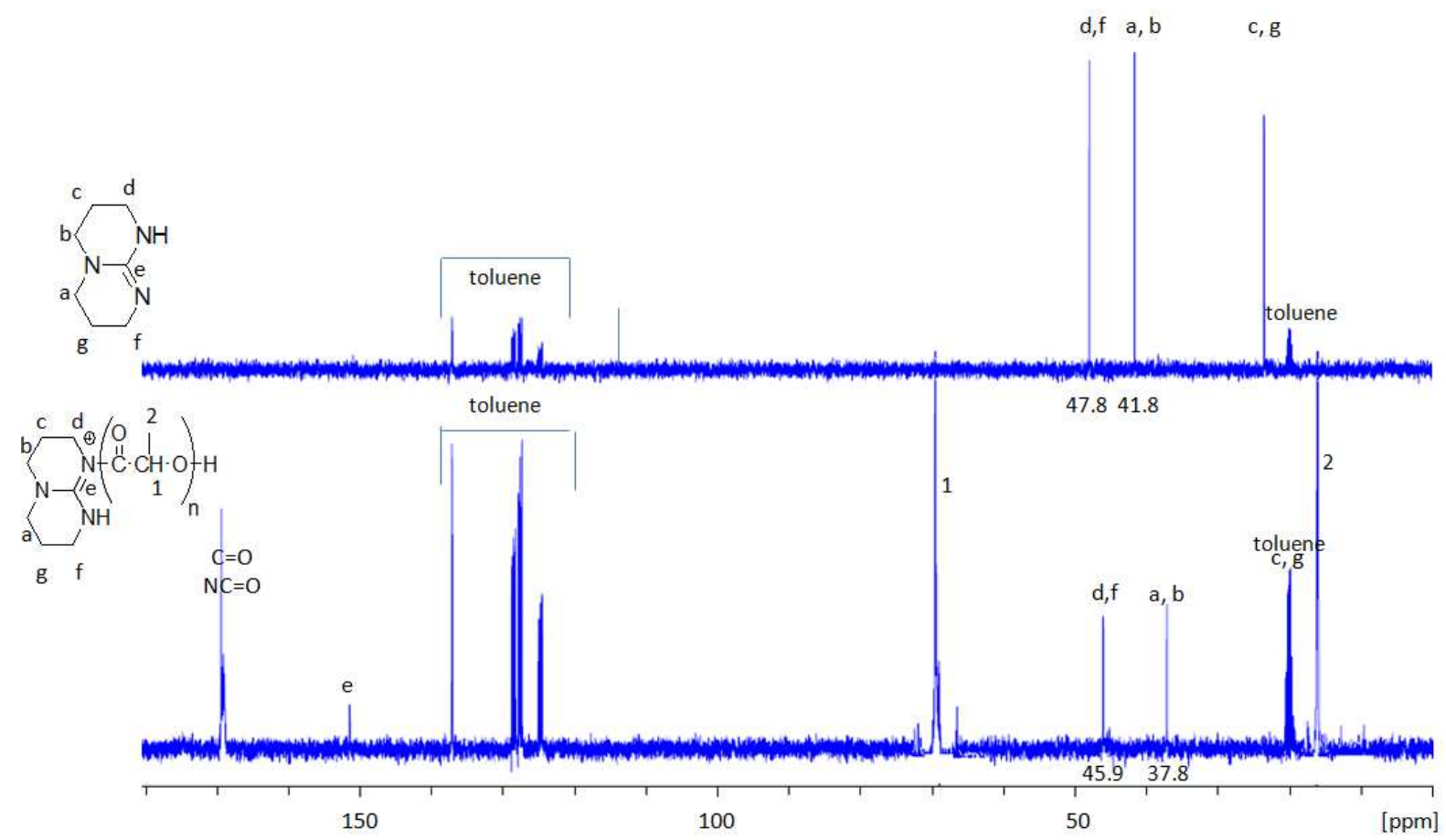

Fig. A.5 HSQC NMR spectrum of PLA after reaction in NMR tube (toluene $\mathrm{d}_{8}, 400 \mathrm{MHz}$ ) 


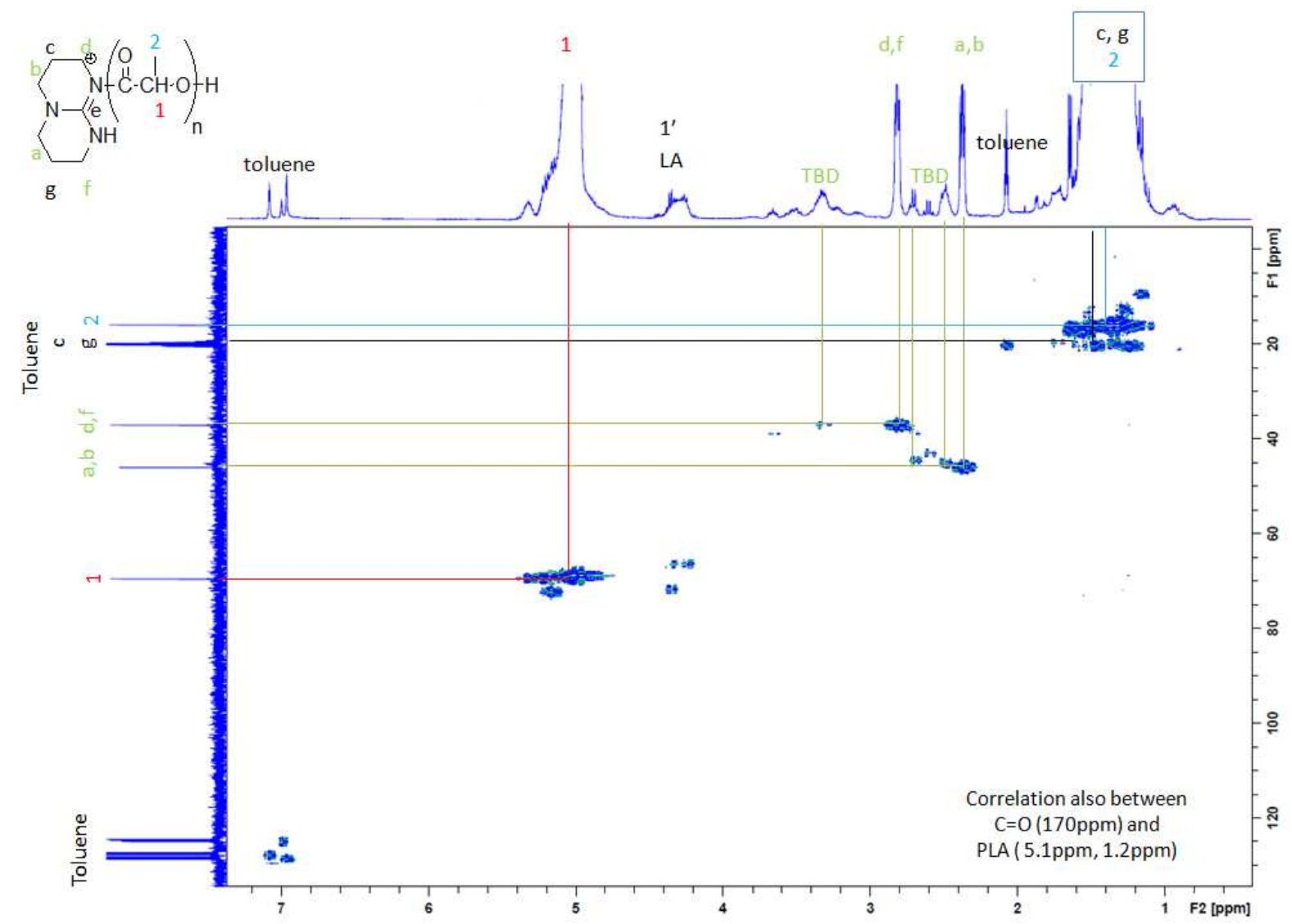

Fig. A.6 DOSY analysis of TBD

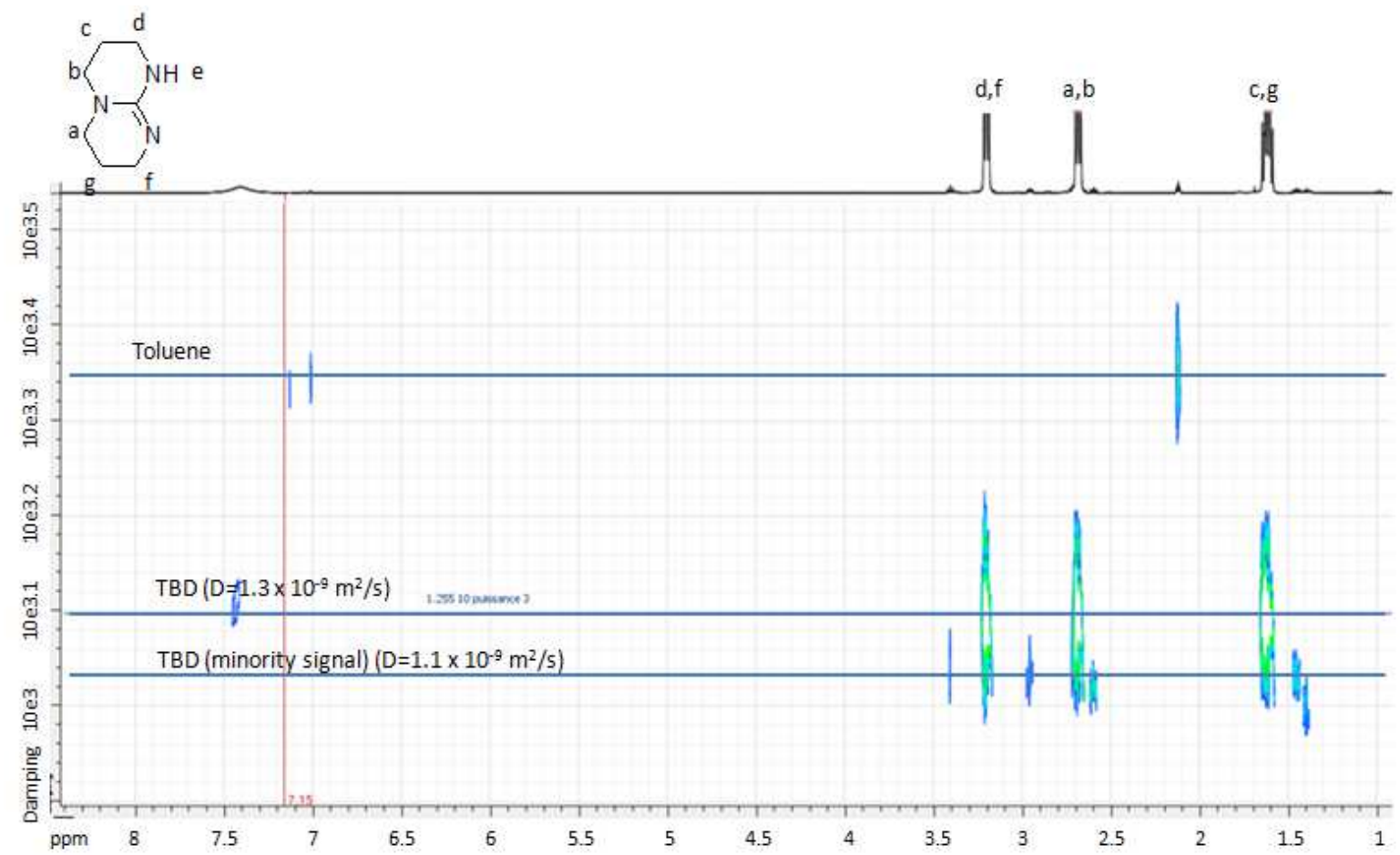


Scheme A.1 Back-bitting mechanism leading to the formation of lactide.<smiles>[B]OC(=O)C(C)OC(=O)C(C)OC(=O)C(C)OC(=O)C(C)C</smiles>

Fig. A.7 MALDI data for the poly(D-lactide) (green) and the Poly(rac-lactide) (red) precursors

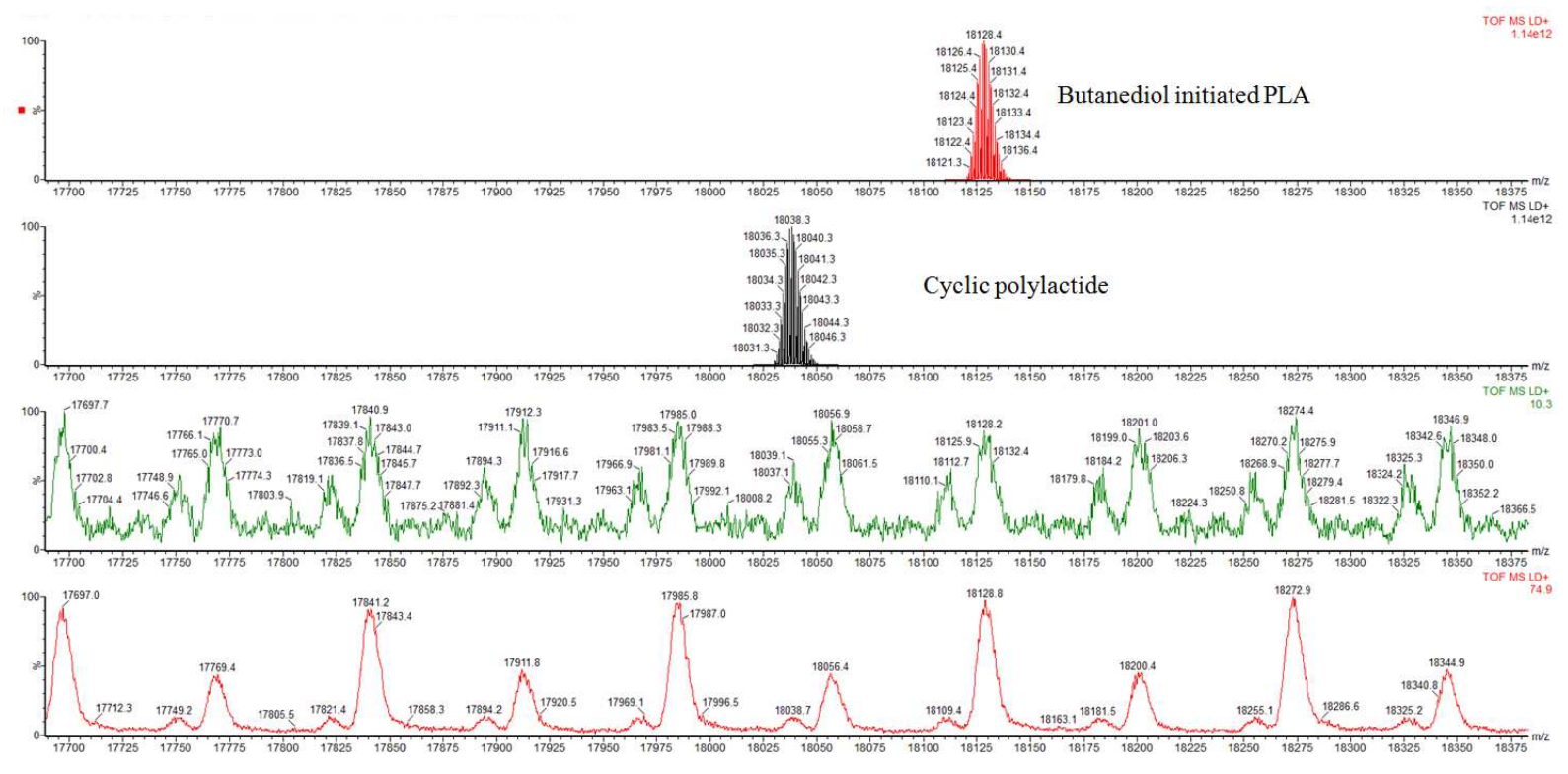




\section{References}

[1] N.E. Kamber, W. Jeong, R.M. Waymouth, R.C. Pratt, B.G.G. Lohmeijer, J.L. Hedrick, Organocatalytic Ring-Opening Polymerization, Chem. Rev. 107 (2007) 5813-5840. https://doi.org/10.1021/cr068415b.

[2] M.K. Kiesewetter, E.J. Shin, J.L. Hedrick, R.M. Waymouth, Organocatalysis: Opportunities and Challenges for Polymer Synthesis, Macromolecules. 43 (2010) 20932107. https://doi.org/10.1021/ma9025948.

[3] A.P. Dove, Organic Catalysis for Ring-Opening Polymerization, ACS Macro Lett. 1 (2012) 1409-1412. https://doi.org/10.1021/mz3005956.

[4] C. Thomas, B. Bibal, Hydrogen-bonding organocatalysts for ring-opening polymerization, Green Chem. 16 (2014) 1687. https://doi.org/10.1039/c3gc41806e.

[5] W.N. Ottou, H. Sardon, D. Mecerreyes, J. Vignolle, D. Taton, Update and challenges in organo-mediated polymerization reactions, Prog. Polym. Sci. 56 (2016) 64-115. https://doi.org/10.1016/j.progpolymsci.2015.12.001.

[6] F. Nederberg, E.F. Connor, M. Möller, T. Glauser, J.L. Hedrick, New paradigms for organic catalysts: the first organocatalytic living polymerization, Angew. Chem. Int. Ed. 40 (2001) 2712-2715.

[7] E.F. Connor, G.W. Nyce, M. Myers, A. Möck, J.L. Hedrick, First Example of NHeterocyclic Carbenes as Catalysts for Living Polymerization: Organocatalytic RingOpening Polymerization of Cyclic Esters, J. Am. Chem. Soc. 124 (2002) 914-915. https://doi.org/10.1021/ja0173324.

[8] B.G.G. Lohmeijer, R.C. Pratt, F. Leibfarth, J.W. Logan, D.A. Long, A.P. Dove, F. Nederberg, J. Choi, C. Wade, R.M. Waymouth, J.L. Hedrick, Guanidine and Amidine Organocatalysts for Ring-Opening Polymerization of Cyclic Esters, Macromolecules. 39 (2006) 8574-8583. https://doi.org/10.1021/ma0619381.

[9] R.C. Pratt, B.G. Lohmeijer, D.A. Long, R.M. Waymouth, J.L. Hedrick, Triazabicyclodecene: A simple bifunctional organocatalyst for acyl transfer and ringopening polymerization of cyclic esters, J. Am. Chem. Soc. 128 (2006) 4556-4557.

[10] H.R. Kricheldorf, N. Lomadze, G. Schwarz, Cyclic Polylactides by Imidazole-Catalyzed Polymerization of L -Lactide, Macromolecules. 41 (2008) 7812-7816. https://doi.org/10.1021/ma801519t.

[11] V. Katiyar, H. Nanavati, Ring-opening polymerization of L-lactide using $\mathrm{N}$-heterocyclic molecules: mechanistic, kinetics and DFT studies, Polym. Chem. 1 (2010) 1491. https://doi.org/10.1039/c0py00125b.

[12] T.S. Stukenbroeker, J.S. Bandar, X. Zhang, T.H. Lambert, R.M. Waymouth, Cyclopropenimine Superbases: Competitive Initiation Processes in Lactide Polymerization, ACS Macro Lett. 4 (2015) 853-856. https://doi.org/10.1021/acsmacrolett.5b00421.

[13] G. Nogueira, A. Favrelle, M. Bria, J.P. Prates Ramalho, P.J. Mendes, A. Valente, P. Zinck, Adenine as an organocatalyst for the ring-opening polymerization of lactide: scope, mechanism and access to adenine-functionalized polylactide, React Chem Eng. 1 (2016) 508-520. https://doi.org/10.1039/C6RE00061D.

[14] P. Lewinski, S. Sosnowski, S. Penczek, I-lactide polymerization - living and controlled catalyzed by initiators: Hydroxyalkylated organic bases, Polymer. 108 (2017) 265-271. https://doi.org/10.1016/j.polymer.2016.11.070. 
[15] L. Simón, J.M. Goodman, The Mechanism of TBD-Catalyzed Ring-Opening Polymerization of Cyclic Esters, J. Org. Chem. 72 (2007) 9656-9662. https://doi.org/10.1021/jo702088c.

[16] C. Bonduelle, B. Martín-Vaca, F.P. Cossío, D. Bourissou, Monomer versus Alcohol Activation in the 4-Dimethylaminopyridine-Catalyzed Ring-Opening Polymerization of Lactide and LacticO-Carboxylic Anhydride, Chem. - Eur. J. 14 (2008) 5304-5312. https://doi.org/10.1002/chem.200800346.

[17] O. Coulembier, P. Dubois, 4-dimethylaminopyridine-based organoactivation: From simple esterification to lactide ring-opening "Living" polymerization, J. Polym. Sci. Part Polym. Chem. 50 (2012) 1672-1680. https://doi.org/10.1002/pola.25949.

[18] N.J. Sherck, H.C. Kim, Y.-Y. Won, Elucidating a Unified Mechanistic Scheme for the DBUCatalyzed Ring-Opening Polymerization of Lactide to Poly(lactic acid), Macromolecules. 49 (2016) 4699-4713. https://doi.org/10.1021/acs.macromol.6b00621.

[19] A. Chuma, H.W. Horn, W.C. Swope, R.C. Pratt, L. Zhang, B.G.G. Lohmeijer, C.G. Wade, R.M. Waymouth, J.L. Hedrick, J.E. Rice, The Reaction Mechanism for the Organocatalytic Ring-Opening Polymerization of L -Lactide Using a Guanidine-Based Catalyst: Hydrogen-Bonded or Covalently Bound?, J. Am. Chem. Soc. 130 (2008) 67496754. https://doi.org/10.1021/ja0764411.

[20] S. Koeller, J. Kadota, A. Deffieux, F. Peruch, S. Massip, J.-M. Léger, J.-P. Desvergne, B. Bibal, Ring-Opening Polymerization of L -Lactide Efficiently Triggered by an AmidoIndole. X-ray Structure of a Complex between L-Lactide and the Hydrogen-Bonding Organocatalyst, J. Am. Chem. Soc. 131 (2009) 15088-15089. https://doi.org/10.1021/ja906119t.

[21] C. Thomas, F. Peruch, A. Deffieux, A. Milet, J.-P. Desvergne, B. Bibal, Phenols and Tertiary Amines: An Amazingly Simple Hydrogen-Bonding Organocatalytic System Promoting Ring Opening Polymerization, Adv. Synth. Catal. 353 (2011) 1049-1054. https://doi.org/10.1002/adsc.201100013.

[22] F. Nederberg, E.F. Connor, T. Glausser, J.L. Hedrick, Organocatalytic chain scission of poly (lactides): a general route to controlled molecular weight, functionality and macromolecular architecture, Chem. Commun. (2001) 2066-2067.

[23] F.A. Leibfarth, N. Moreno, A.P. Hawker, J.D. Shand, Transforming polylactide into valueadded materials, J. Polym. Sci. Part Polym. Chem. 50 (2012) 4814-4822. https://doi.org/10.1002/pola.26303.

[24] T. Tsukegi, T. Motoyama, Y. Shirai, H. Nishida, T. Endo, Racemization behavior of I,Ilactide during heating, Polym. Degrad. Stab. 92 (2007) 552-559. https://doi.org/10.1016/j.polymdegradstab.2007.01.009.

[25] I.A. Shuklov, H. Jiao, J. Schulze, W. Tietz, K. Kühlein, A. Börner, Studies on the epimerization of diastereomeric lactides, Tetrahedron Lett. 52 (2011) 1027-1030. https://doi.org/10.1016/j.tetlet.2010.12.094.

[26] J.-B. Zhu, E.Y.-X. Chen, From meso -Lactide to Isotactic Polylactide: Epimerization by B/N Lewis Pairs and Kinetic Resolution by Organic Catalysts, J. Am. Chem. Soc. 137 (2015) 12506-12509. https://doi.org/10.1021/jacs.5b08658.

[27] HansR. Kricheldorf, A. Serra, Polylactones: 6. Influence of various metal salts on the optical purity of poly(L-lactide), Polym. Bull. 14 (1985) 487-502. https://doi.org/10.1007/BF00271606.

[28] R. Mincheva, J.-M. Raquez, V. Lison, E. Duquesne, O. Talon, P. Dubois, Stereocomplexes from Biosourced Lactide/Butylene Succinate-Based Copolymers and Their Role as 
Crystallization Accelerating Agent, Macromol. Chem. Phys. 213 (2012) 643-653. https://doi.org/10.1002/macp.201100620.

[29] A. Kowalski, A. Duda, S. Penczek, Polymerization of I,I-Lactide Initiated by Aluminum Isopropoxide Trimer or Tetramer, Macromolecules. 31 (1998) 2114-2122. https://doi.org/10.1021/ma971737k.

[30] L.-D. Feng, B. Sun, X.-C. Bian, Z.-M. Chen, X.-S. Chen, Determination of d-lactate content in poly(lactic acid) using polarimetry, Polym. Test. 29 (2010) 771-776. https://doi.org/10.1016/j.polymertesting.2010.06.005.

[31] B. Eling, S. Gogolewski, A.J. Pennings, Biodegradable materials of poly(l-lactic acid): 1. Melt-spun and solution-spun fibres, Polymer. 23 (1982) 1587-1593. https://doi.org/10.1016/0032-3861(82)90176-8.

[32] E.J. Ebbers, G.J.A. Ariaans, J.P.M. Houbiers, A. Bruggink, B. Zwanenburg, Controlled racemization of optically active organic compounds: Prospects for asymmetric transformation, Tetrahedron. 53 (1997) 9417-9476. https://doi.org/10.1016/S00404020(97)00324-4.

[33] K.A. Thakur, R.T. Kean, E.S. Hall, J.J. Kolstad, T.A. Lindgren, M.A. Doscotch, J.I. Siepmann, E.J. Munson, High-resolution $13 \mathrm{C}$ and $1 \mathrm{H}$ solution NMR study of poly (lactide), Macromolecules. 30 (1997) 2422-2428.

[34] U. Schuchardt, R.M. Vargas, G. Gelbard, Alkylguanidines as catalysts for the transesterification of rapeseed oil, J. Mol. Catal. Chem. 99 (1995) 65-70. https://doi.org/10.1016/1381-1169(95)00039-9.

[35] S. Kafka, B. Larissegger-Schnell, T. Kappe, Synthesis of highly symmetric mesomeric triazaphenalene betaines, J. Heterocycl. Chem. 41 (2004) 717-721. https://doi.org/10.1002/jhet.5570410511.

[36] M.P. Coles, Bicyclic-guanidines, -guanidinates and -guanidinium salts: wide ranging applications from a simple family of molecules, Chem. Commun. (2009) 3659. https://doi.org/10.1039/b901940e.

[37] M.K. Kiesewetter, M.D. Scholten, N. Kirn, R.L. Weber, J.L. Hedrick, R.M. Waymouth, Cyclic Guanidine Organic Catalysts: What Is Magic About Triazabicyclodecene?, J. Org. Chem. 74 (2009) 9490-9496. https://doi.org/10.1021/jo902369g.

[38] Y. Fan, H. Nishida, Y. Shirai, T. Endo, Control of racemization for feedstock recycling of PLLA, Green Chem. 5 (2003) 575-579. https://doi.org/10.1039/B304792J.

[39] Y. Fan, Racemization on thermal degradation of poly(?-lactide) with calcium salt end structure, Polym. Degrad. Stab. 80 (2003) 503-511. https://doi.org/10.1016/S01413910(03)00033-8.

[40] H. Urayama, T. Kanamori, Y. Kimura, Microstructure and Thermomechanical Properties of Glassy Polylactides with Different Optical Purity of the Lactate Units, Macromol. Mater. Eng. 286 (2001) 705. https://doi.org/10.1002/14392054(20011101)286:11<705::AID-MAME705>3.0.CO;2-Q.

[41] J.-R. Sarasua, R.E. Prud'homme, M. Wisniewski, A. Le Borgne, N. Spassky, Crystallization and Melting Behavior of Polylactides, Macromolecules. 31 (1998) 3895-3905. https://doi.org/10.1021/ma971545p.

[42] E.W. Fischer, H.J. Sterzel, G. Wegner, Investigation of the structure of solution grown crystals of lactide copolymers by means of chemical reactions, Kolloid-Z U Z Polym. 251 (1973) 980-990. 
[43] D.E. Niehaus, C. Jackson, Size exclusion chromatography of step-growth polymers with cyclic species: theoretical model and data analysis methods, Polymer. 41 (2000) 259268.

[44] H. Nishida, T. Mori, S. Hoshihara, Y. Fan, Y. Shirai, T. Endo, Effect of tin on poly(I-lactic acid) pyrolysis, Polym. Degrad. Stab. 81 (2003) 515-523. https://doi.org/10.1016/S0141-3910(03)00152-6.

[45] F.-D. Kopinke, M. Remmler, K. Mackenzie, M. Möder, O. Wachsen, Thermal decomposition of biodegradable polyesters-II. Poly(lactic acid), Polym. Degrad. Stab. 53 (1996) 329-342. https://doi.org/10.1016/0141-3910(96)00102-4.

[46] L.A. Román-Ramírez, P. Mckeown, M.D. Jones, J. Wood, Poly(lactic acid) Degradation into Methyl Lactate Catalyzed by a Well-Defined Zn(II) Complex, ACS Catal. 9 (2019) 409-416. https://doi.org/10.1021/acscatal.8b04863.

[47] P. McKeown, L.A. Román-Ramírez, S. Bates, J. Wood, M.D. Jones, Zinc Complexes for PLA Formation and Chemical Recycling: Towards a Circular Economy, ChemSusChem. 12 (2019) 5233-5238. https://doi.org/10.1002/cssc.201902755.

[48] H. Tsuji, H. Daimon, K. Fujie, A New Strategy for Recycling and Preparation of Poly( L lactic acid): Hydrolysis in the Melt, Biomacromolecules. 4 (2003) 835-840. https://doi.org/10.1021/bm034060j.

[49] A.-F. Mohd-Adnan, H. Nishida, Y. Shirai, Evaluation of kinetics parameters for poly(Ilactic acid) hydrolysis under high-pressure steam, Polym. Degrad. Stab. 93 (2008) 10531058. https://doi.org/10.1016/j.polymdegradstab.2008.03.022.

[50] V. Piemonte, F. Gironi, Kinetics of Hydrolytic Degradation of PLA, J. Polym. Environ. 21 (2013) 313-318. https://doi.org/10.1007/s10924-012-0547-x. 